\title{
Hysteresis Current Control of Switched Reluctance Motor in Aircraft Applications
}

\author{
Maged N. F. Nashed, Samia M. Mahmoud, Mohsen Z. El-Sherif, \\ Emad S. Abdel-Aliem \\ ${ }^{1}$ Assoc. Prof., Dep. of Power Electronic and Energy Conversion, Electronics Research Institute, Cairo, Egypt \\ ${ }^{2}$ Lecturer, Dep. of Electrical Engineering, Shoubra Faculty of Engineering, Benha University, Cairo, Egypt \\ ${ }^{3}$ Professor, Dep. of Electrical Engineering, Shoubra Faculty of Engineering, Benha University, Cairo, Egypt \\ ${ }^{4}$ Ass. Lect., Dep. of Electrical Engineering, Shoubra Faculty of Engineering, Benha University, Cairo, Egypt
}

\begin{abstract}
The switched reluctance motor (SRM) drives have been widely used in aircraft applications due to the motor advantages like high speed operation, simple construction, no windings on rotor. But high torque ripples and acoustic noise are main disadvantages. The current hysteresis chopping control is one of the important control methods for SRM drives. These disadvantages can be limited using the hysteresis or chopping current control. This control strategy makes the torque of SRM maintained within a set of hysteresis bands by applying suitable source voltage. This paper introduces two hysteresis control modes; hard chopping and soft chopping mode. The SRM drive system is modeled in Simulink model using MATLAB/SIMULINK software package.
\end{abstract}

Keywords: - Hysteresis/Chopping control, hard chopping, soft chopping, comparator, current controller

\section{INTRODUCTION}

One of the most applications of SRM in aircraft is using the SRM coupled with DC generator through high speed gear box to drive the generator. This DC generator may be interfaced with a three-phase $115 \mathrm{~V}$ lines through a four-quadrant drive to be used in another aircraft application. The SRM is operated as a source of torque, and the DC generator regulates the system speed. The SRM is driven by its converter synchronized by the control and the resolver on the motor's shaft. This electric drive system has been recognized to provide benefits in system efficiency, weight and size, and flexibility in speed control of SRM. Fig. 1 shows the basic components of the motor drive system. These components are 3-ph 6/4 SRM, asymmetric DC-DC IGBT converter, gear box, DC machine works as generator and also the electronic control that contain comparator, and the current controller.

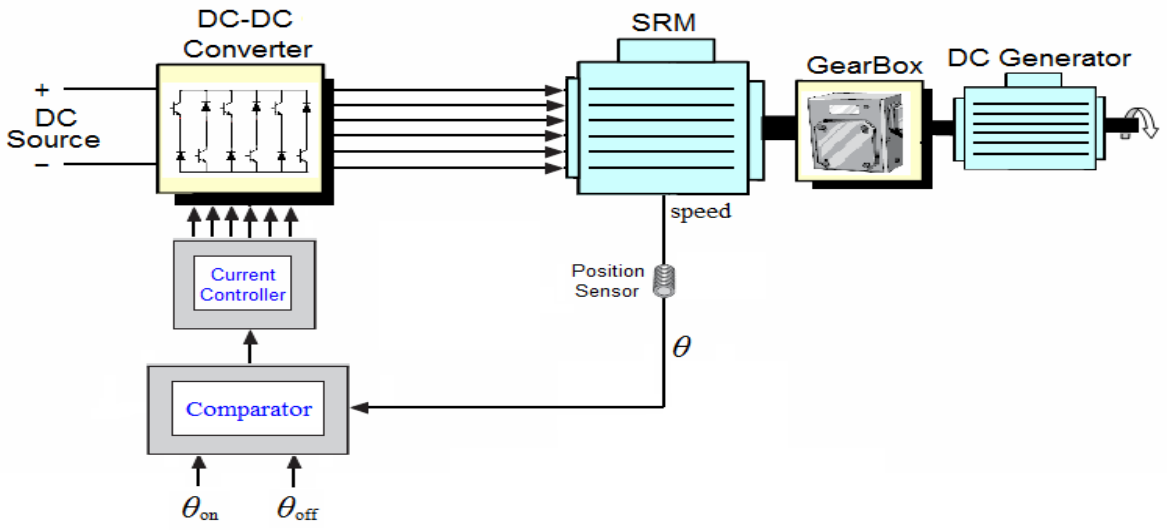

Fig. 1 The SRM drive system in aircraft application

The DC-DC converter and SRM are explained in details in [1]. The standard voltages of the converter used in aircraft are: 270, 350 and 540V [2]. The SRM parameters are mentioned in Appendix (A). The comparator regulates the motor performance via comparing the measured rotor position $\theta$, switching turn-on angle $\theta_{o n}$, and switching turn-off angle $\theta_{o f f}$ [3]-[5]. The comparator can be implemented experimentally using a programmed computer connected to a controller that follows the commands of the simulated program in this computer [6]. Rotor position sensor is an integral part of SRM control system mounted on the rotor to determine turn-on and turn-off angles to excite and commutate the phase windings. Usually, optical encoders, resolver, or 
hall-effect sensors mounted on the shaft are used to obtain rotor position information [3,4,7]. The SRM and the DC generator speeds are never the same, so, a gear box system is used between the motor and the generator's rotor to protect it from an excessive wear and tear. The gear system helps the generator's rotor to run at the generator's rated speed $[5,6]$. This gearbox is essential to ensure that the generator speed is constant irrespective of the SRM speed and aircraft status [2].

\section{PRINCIPLE OF HYSTERESIS CURRENT CONTROL}

Hysteresis/chopping current control is a control strategy used with SRM for controlling the phase's currents to be within a band around a reference value [8]. This strategy is preferable over wide speed range for SRM operation because the desired current can be easily reached. The control strategy based on turning on the switches of the converter when the phase current is lower than a lower band limit, and turning off these switches when the current is above an upper band limit $[9,10]$. The lower limit and the upper limit can be obtained according to the control requirements and the switching frequency of the power converter of SRM [4].

The hysteresis control implemented through using two modes; soft and hard chopping which are illustrated in Fig. 2a, 2b [14]. The soft chopping and hard chopping that can be easily used with the asymmetric bridge converter. Fig. 2c shows the asymmetric converter has two switches per phase and the hysteresis band. It achieves all forms of control, including hard and soft chopping [11]. In chopping control of Fig. 2c; the phase current is controlled between two levels (i.e., the upper limit and the lower limit) equal to $i_{r e f, j} \pm \Delta \mathrm{i} / 2$, where $i_{r e f, j}$ is the reference current of each phase and $\Delta \mathrm{i} / 2$ is the hysteresis band that has an acceptable range around the reference current [4].

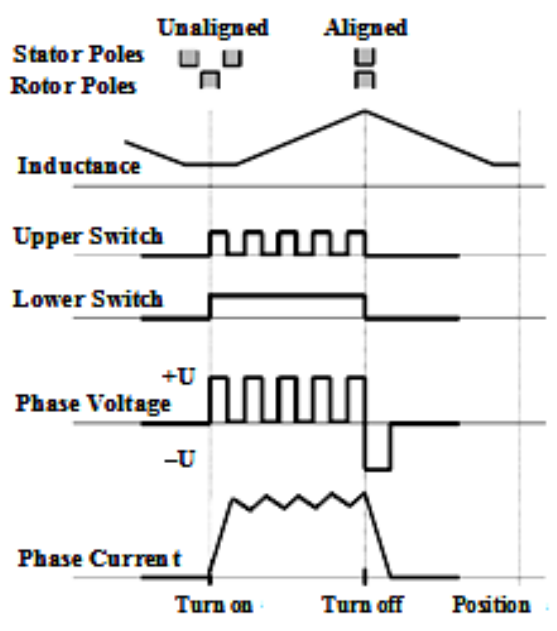

(a) Soft chopping

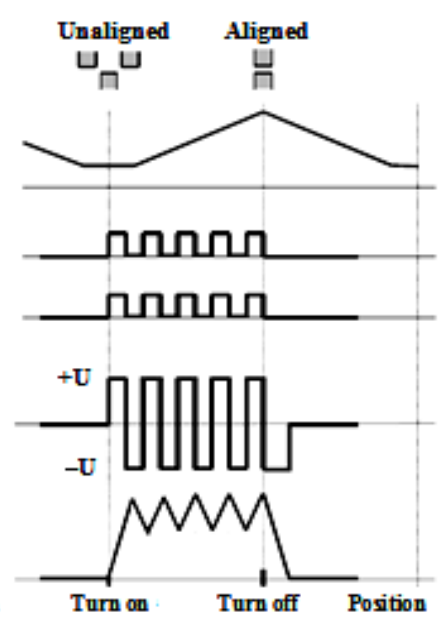

(b) Hard chopping
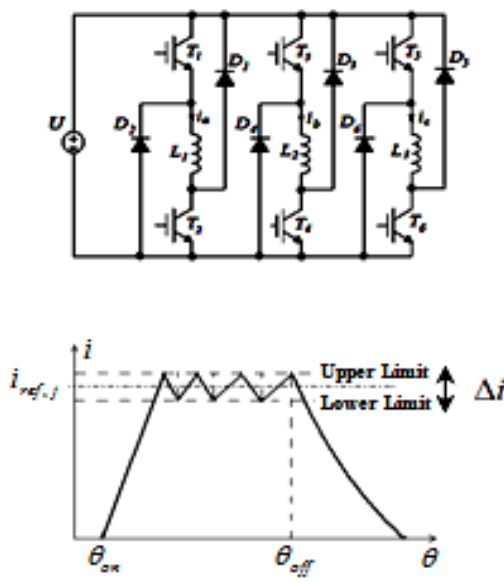

(c) Converter and hysteresis band

Fig. 2 SRM drive using soft chopping and hard chopping control

This hysteresis current control is achieved with a closed-loop control by one of the two modes of a chopping action; hard chopping mode or soft chopping mode.

- In soft chopping mode: Fig. 2a, the phase voltage is switched between (zero) and (+U) value. For phase of inductance $L_{1}$, the lower switch $T_{2}$ is left on during phase conducting period and the upper switch $T_{1}$ is chopped according to the pulsed signal. It allows not only control of the current but also minimize the ripple current. Also, it produces lower acoustic noise and less electromagnetic interference (EMI). Therefore, soft switching is often preferred for motoring operation [12].

- In hard chopping mode: Fig. $2 b$, the phase voltage is switched between $(-U)$ and $(+U)$ value. For phase inductance $L_{l}$, both switches $T_{1}$ and $T_{2}$ are switching on during the conducting period. So, $(+\mathrm{U})$ voltage is applied to conducting phase when $T_{1}$ and $T_{2}$ are on, and (-U) voltage is applied when $T_{1}$ and $T_{2}$ are off before the phase current drops to zero. It has large value of current ripples. It can be applied in braking operation [13].

\section{HARD CHOPPING CONTROL OF CURRENT AT NO-LOAD}

The Simulink block control diagram when hysteresis current control (hard chopping) is used for three phases 6/4 SRM at no load is shown in Fig. 3. The data required for this motor in the following block control diagram is mentioned in Appendix (A). The most significant parameter in this drive system of the hysteresis controller is the hysteresis band which is desired to be as small as possible in order to reduce the current ripple. Also, selecting the proper switching strategy, dwell angle, voltage source, and switching angles will improve the 
overall efficiency of the drive system. The main idea of current control is to produce a total torque as steady as possible in non linear operation; as if the motor operates in linear mode of operation. This linearity of torque depends on choosing switching angles to make the current of the phases at commutation producing a total current nearly as dc current in order to maximize the motor total torque. So, the used switching angles are turnon angle, $\theta_{\text {on }}=45^{\circ}$, and turn-off angle, $\theta_{\text {off }}=80^{\circ}$.

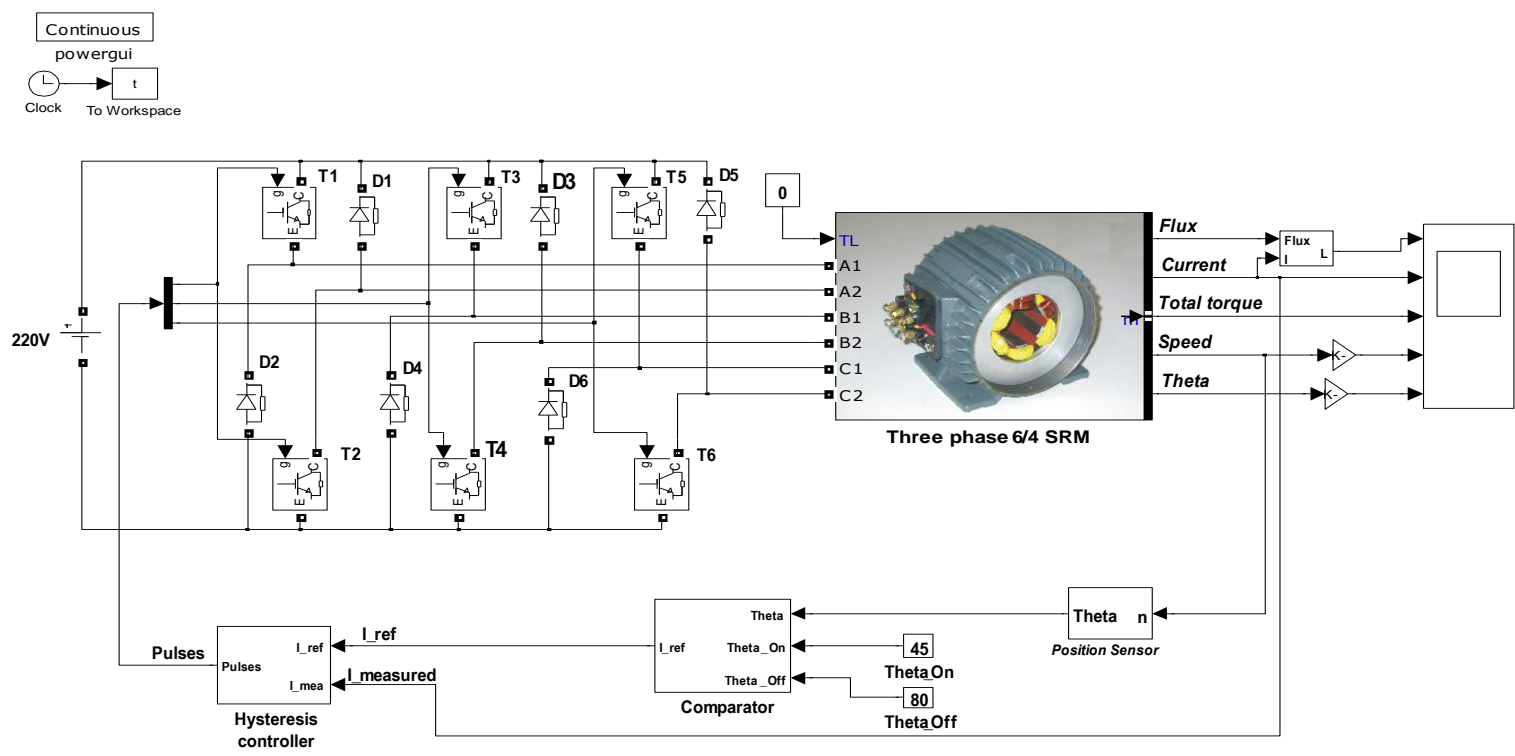

Fig. 3 Simulink model using hard chopping control for 3-ph 6/4 SRM at no-load

\section{A. Hard chopping control with source voltage of $220 \mathrm{~V}$}

The phase's inductances, voltages and currents against rotor position at no load using hard chopping control are shown in Fig. 4, where the rated converter voltage is $220 \mathrm{~V}$, but this voltage will be increased with loaded motor to increase the gradient of motor phase's currents producing flat-topped total current. The hard chopping mode is more suitable for braking operation to hold on the load torque and to provide motor operation at zero speed. The motor characteristics: inductance, phase voltage, phase current, torque, and speed will be obtained at using the DC source voltage values 220, 350 and 540V. The last two values of the source voltage are used in aircraft applications.

Motor total torque versus rotor position using hard chopping at no-load with source voltage of $220 \mathrm{~V}$ is shown in Fig. 5. The torque ripple is small; also, the torque becomes more stable. The motor speed reaches its steady state after a number of revolutions less than seven complete revolutions of the rotor; as shown in Fig. 6. Motor phase current versus phase flux-linkage is shown in Fig. 7. Hard chopping control makes the envelope area in this Fig. 7 as maximum as possible, that means, motor total torque not decreased as rotor position changes.
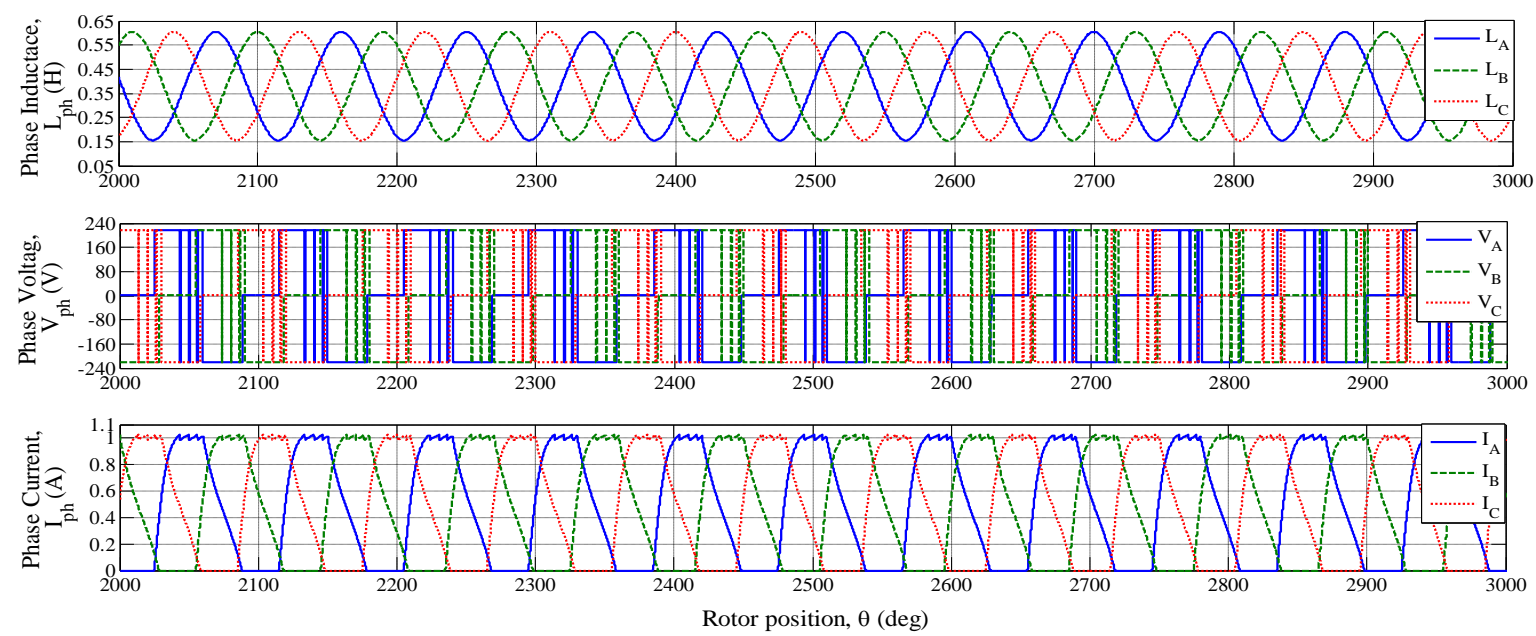

Fig. 4 Instantaneous phases inductances, voltages, and currents versus rotor position using hard chopping control at $\mathrm{U}_{\mathrm{dc}}=220 \mathrm{~V}$ 


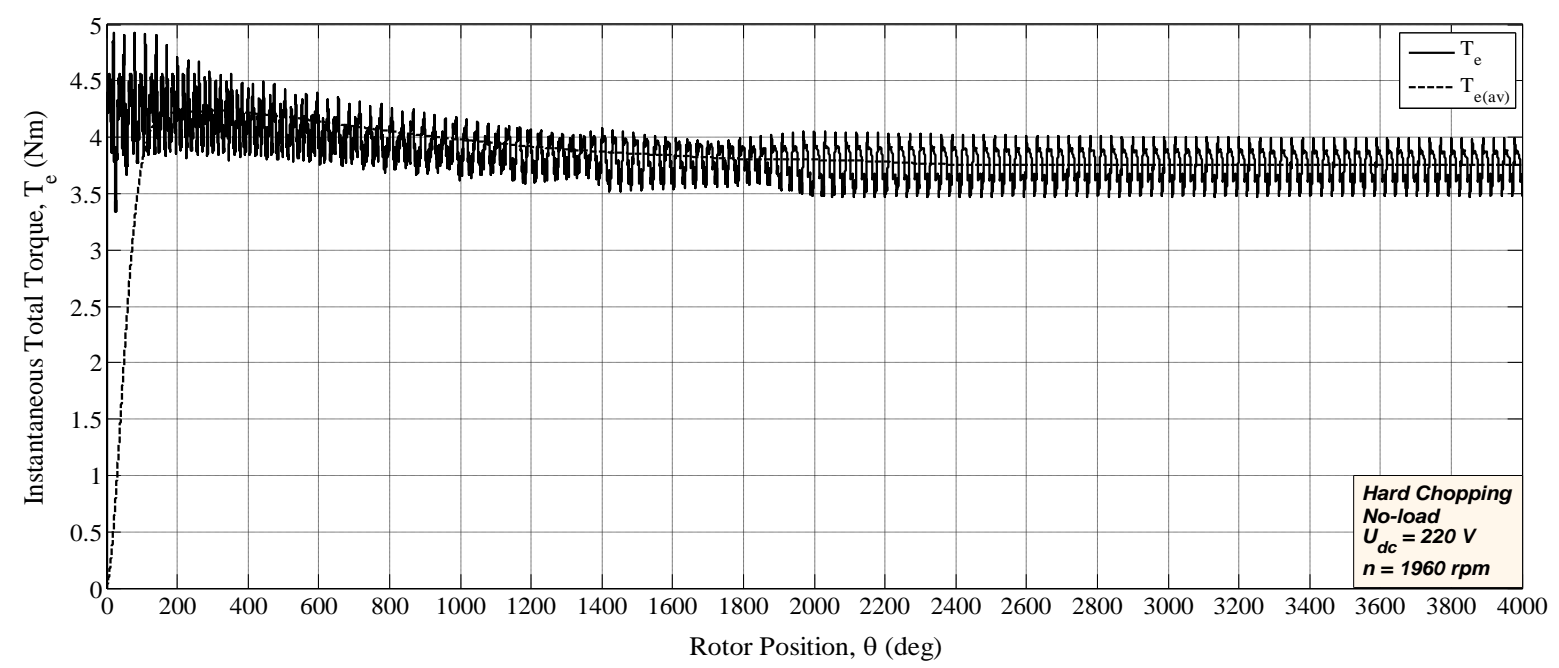

Fig. 5 Instantaneous total torque versus rotor position using hard chopping control at $U_{\mathrm{dc}}=220 \mathrm{~V}$

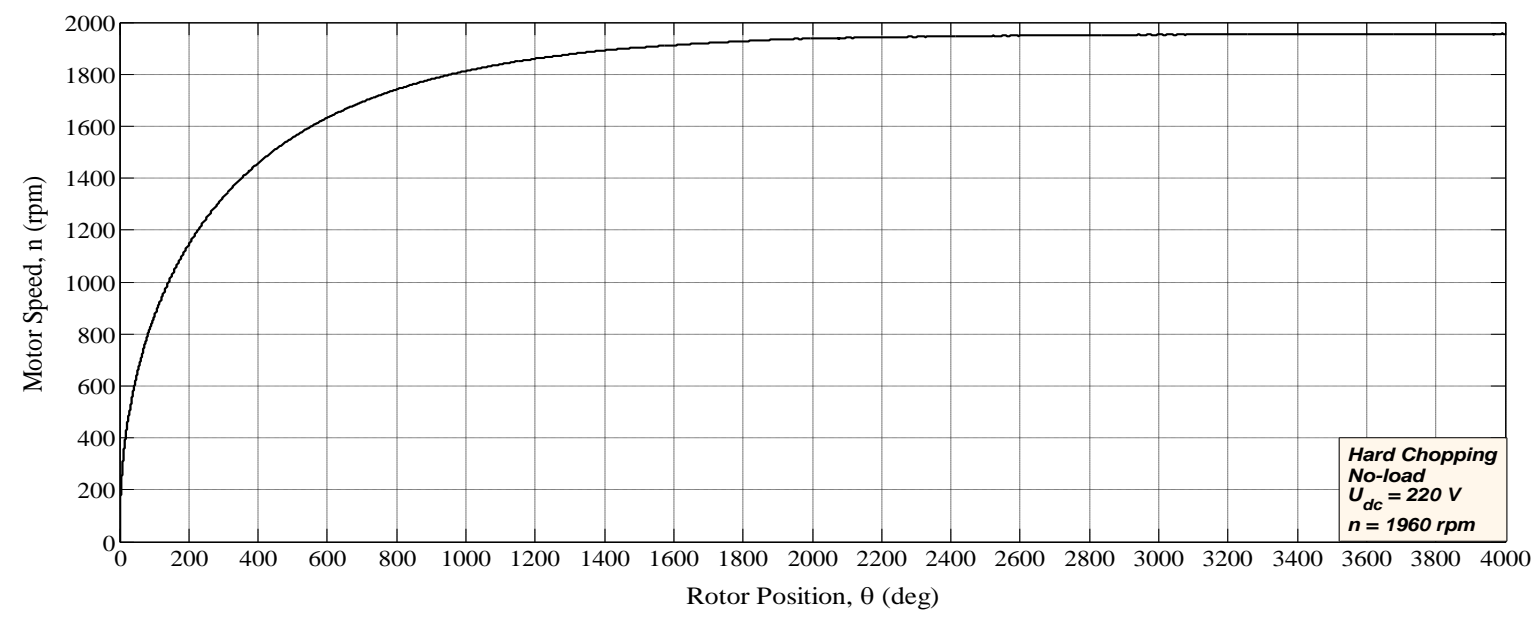

Fig. 6 Motor speed versus rotor position using hard chopping control at $\mathrm{U}_{\mathrm{dc}}=220 \mathrm{~V}$

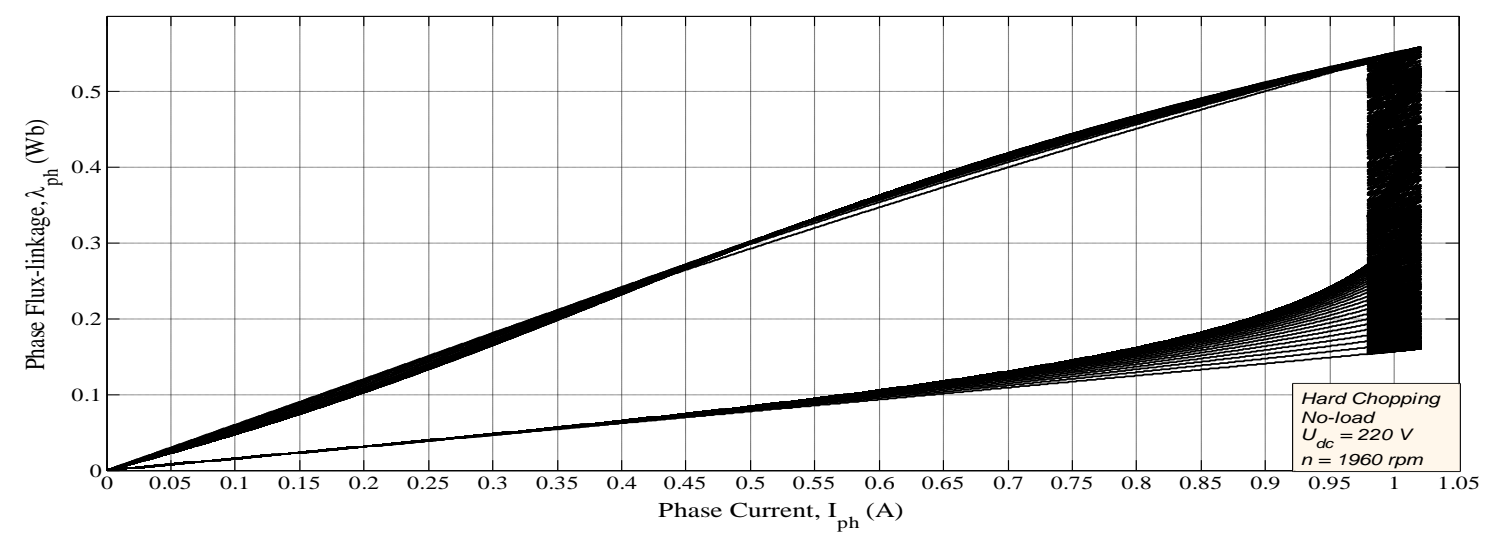

Fig. 7 Phase flux-linkage versus phase current using hard chopping control at $U_{\mathrm{dc}}=220 \mathrm{~V}$

\section{B. Hard chopping control with source voltage of $350 \mathrm{~V}$}

The simulation is repeated in this section under the same conditions as before while allowing the phase currents to overlap at applied higher value of source voltage 350V. Motor characteristics; phase inductance, phase voltage, and phase current versus rotor position are shown in Fig. 8. Increasing value of the source voltage will result in an increase of the gradient of the phase current. The motor total torque versus rotor position is shown in Fig. 9. It is noticed that the total torque reaches to steady state faster than the case when the source voltage is $220 \mathrm{~V}$. But the total torque has larger ripple. 

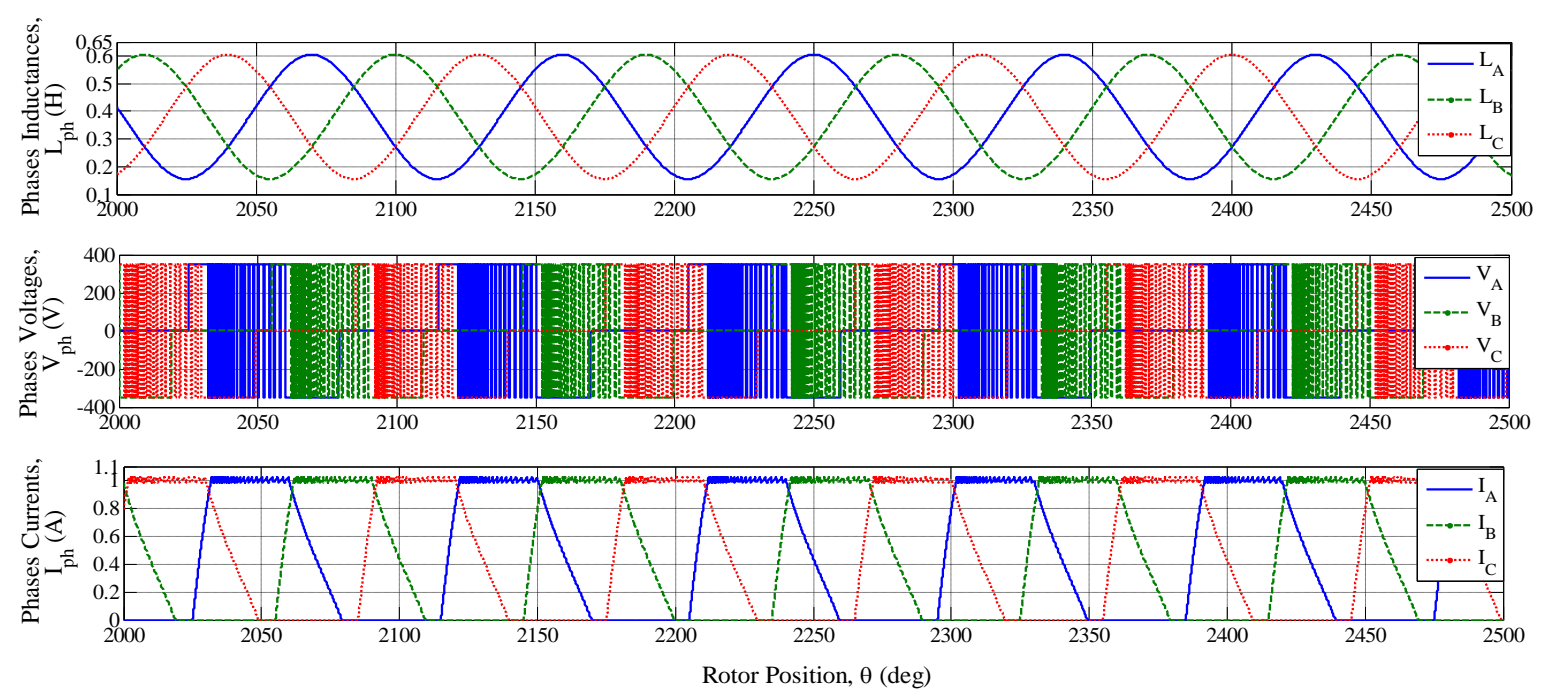

Fig. 8 Instantaneous phases inductances, voltages, and currents versus rotor position using hard chopping control at $\mathrm{U}_{\mathrm{dc}}=350 \mathrm{~V}$

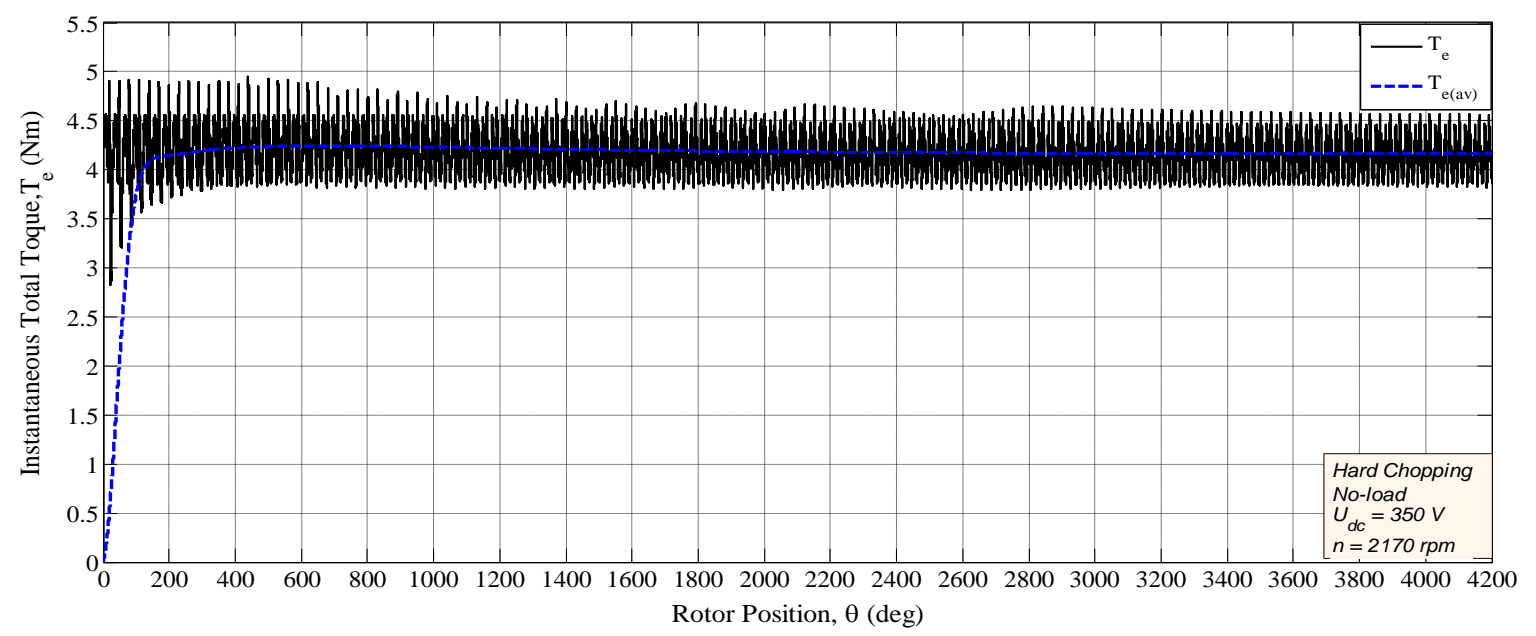

Fig. 9 Instantaneous total torque versus rotor position using hard chopping control at $\mathrm{U}_{\mathrm{dc}}=350 \mathrm{~V}$

From Fig. 10, the motor speed reaches its steady state after about eleven revolutions. The steady state value of speed becomes $2170 \mathrm{rpm}$ that increases further with increasing the supply voltage. The phase fluxlinkage versus the phase current at $350 \mathrm{~V}$ is shown in Fig. 11. In this case when the supply voltage equals $350 \mathrm{~V}$, the envelope area is larger than that case when the supply voltage is equal to $220 \mathrm{~V}$.

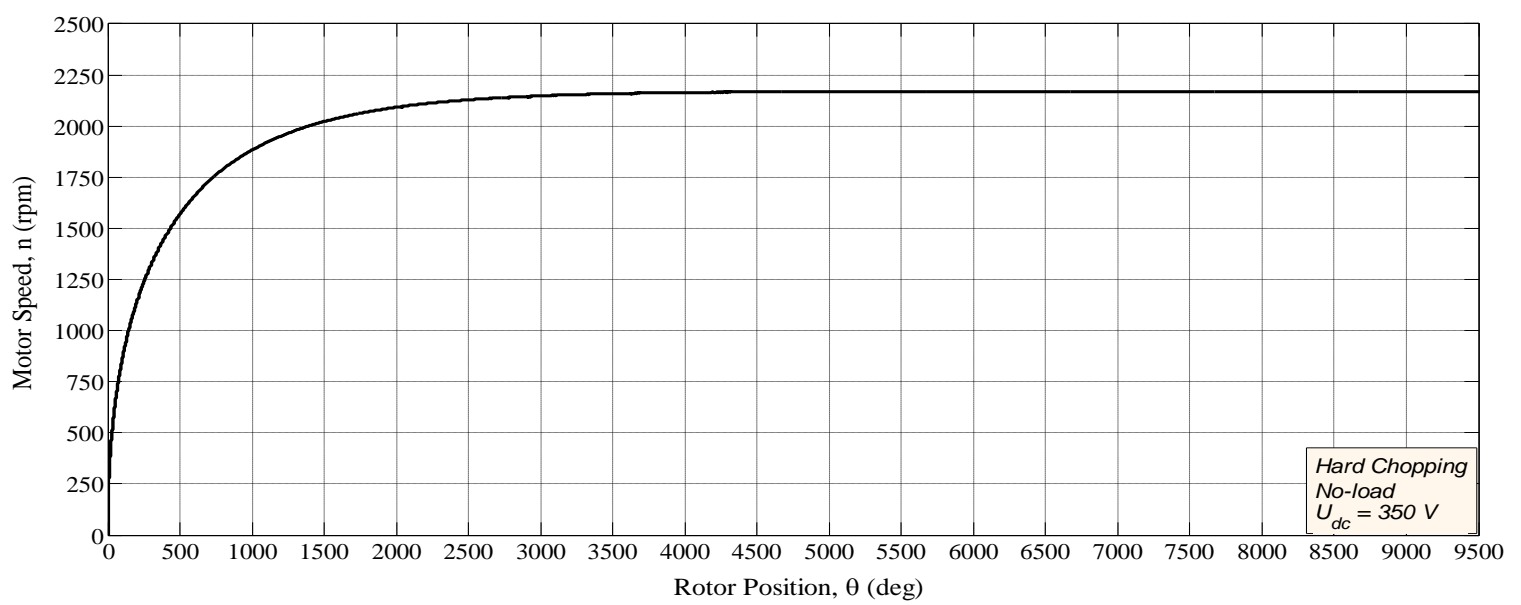

Fig. 10 Motor speed versus rotor position using hard chopping control at $\mathrm{U}_{\mathrm{dc}}=350 \mathrm{~V}$ 


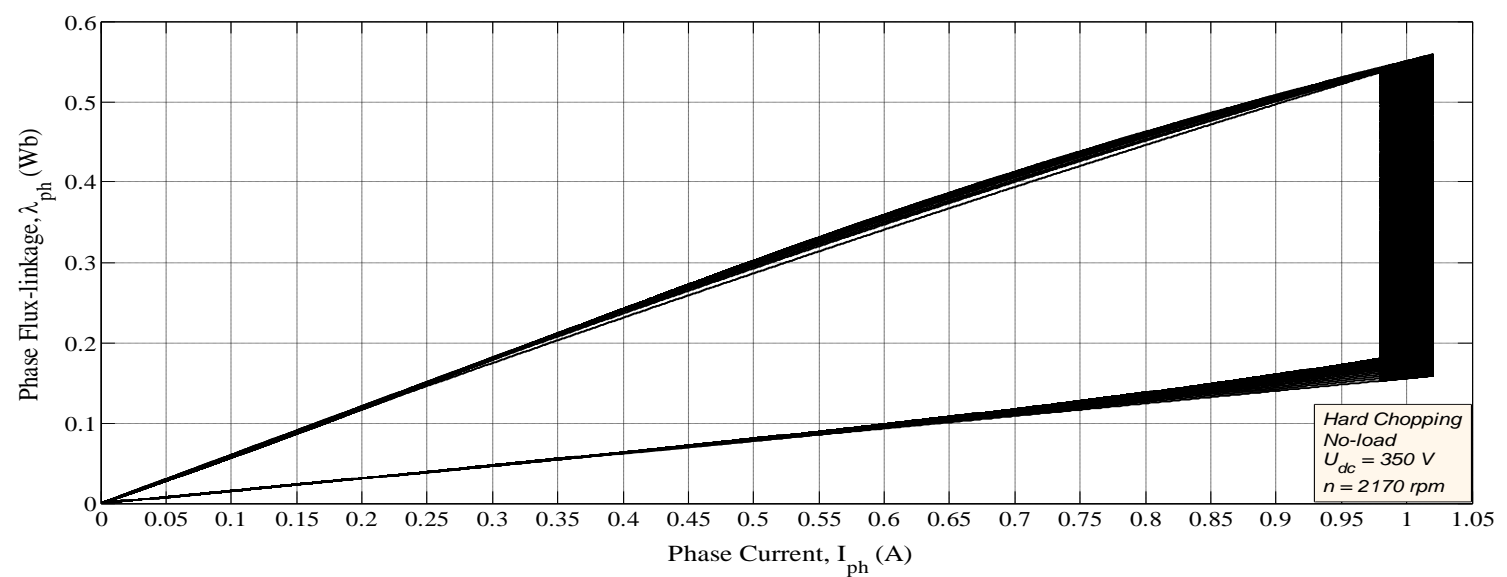

Fig. 11 Phase flux-linkage versus phase current using hard chopping control at $\mathrm{U}_{\mathrm{dc}}=350 \mathrm{~V}$

\section{Hard chopping control with source voltage of $540 \mathrm{~V}$}

The simulation for obtain machine characteristics is repeated at applied higher value of source voltage $540 \mathrm{~V}$. Motor characteristics; phase inductance, phase voltage, and phase current versus rotor position are shown in Fig. 12. Increasing value of the source voltage will result in further increase in the gradient of the phase current.
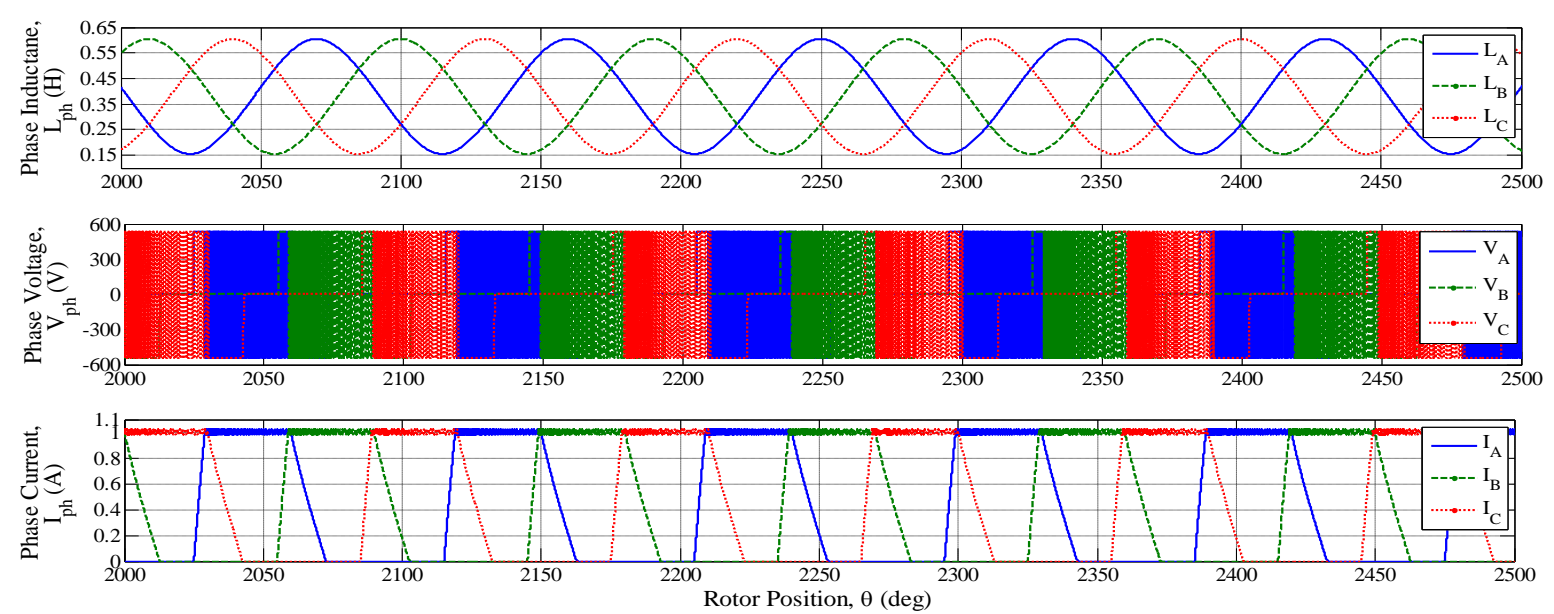

Fig. 12 Instantaneous phases inductances, voltages, and currents versus rotor position using hard chopping control at $\mathrm{U}_{\mathrm{dc}}=540 \mathrm{~V}$

The motor total torque versus rotor position is shown in Fig. 13, where the steady state reaches faster than the two cases of applying $220 \mathrm{~V}$ and $350 \mathrm{~V}$ but with larger ripples. The motor speed reaches its steady state value of $2220 \mathrm{rpm}$ after fifteen revolutions as shown Fig. 14. The steady state speed becomes $2220 \mathrm{rpm}$ that increases further with increasing supply voltage. The phase flux-linkage versus phase current at $540 \mathrm{~V}$ is shown in Fig. 15.

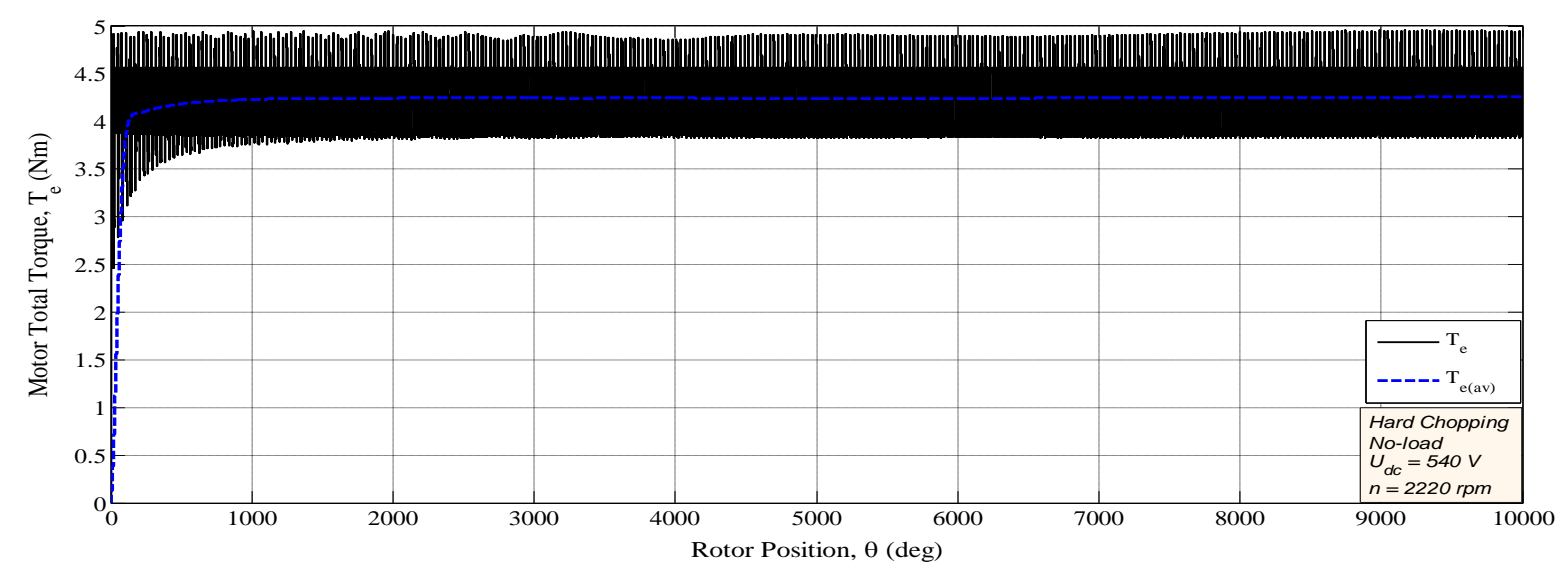

Fig. 13 Instantaneous total torque versus rotor position using hard chopping control at $\mathrm{U}_{\mathrm{dc}}=540 \mathrm{~V}$ 


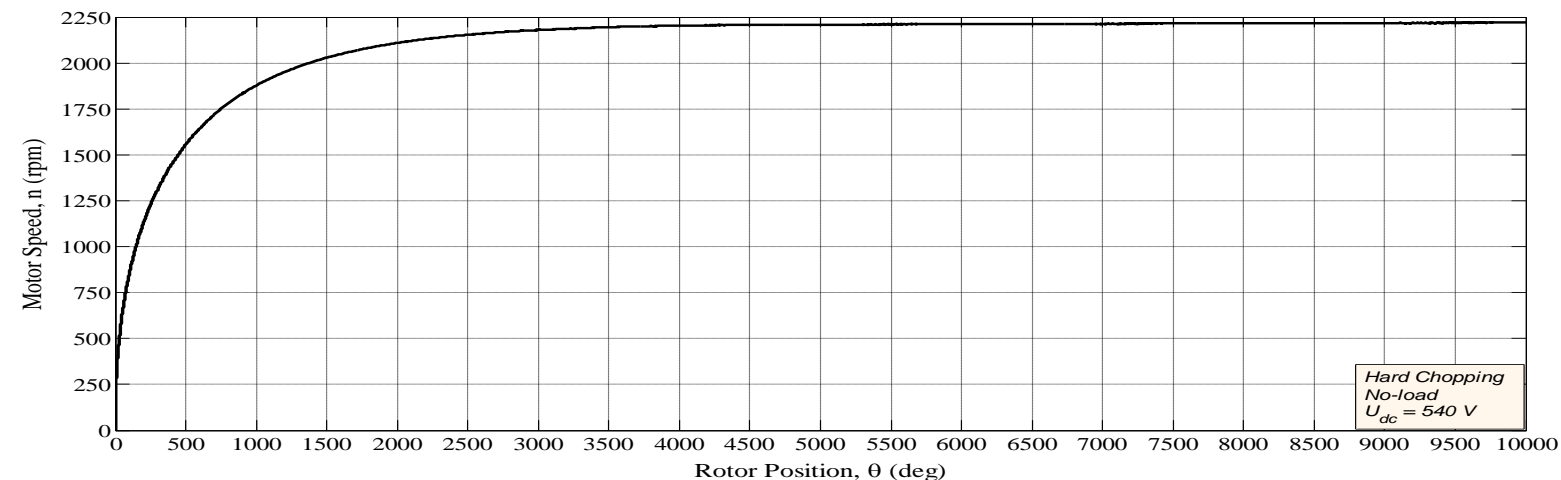

Fig. 14 Motor speed versus rotor position using hard chopping control at $\mathrm{U}_{\mathrm{dc}}=540 \mathrm{~V}$

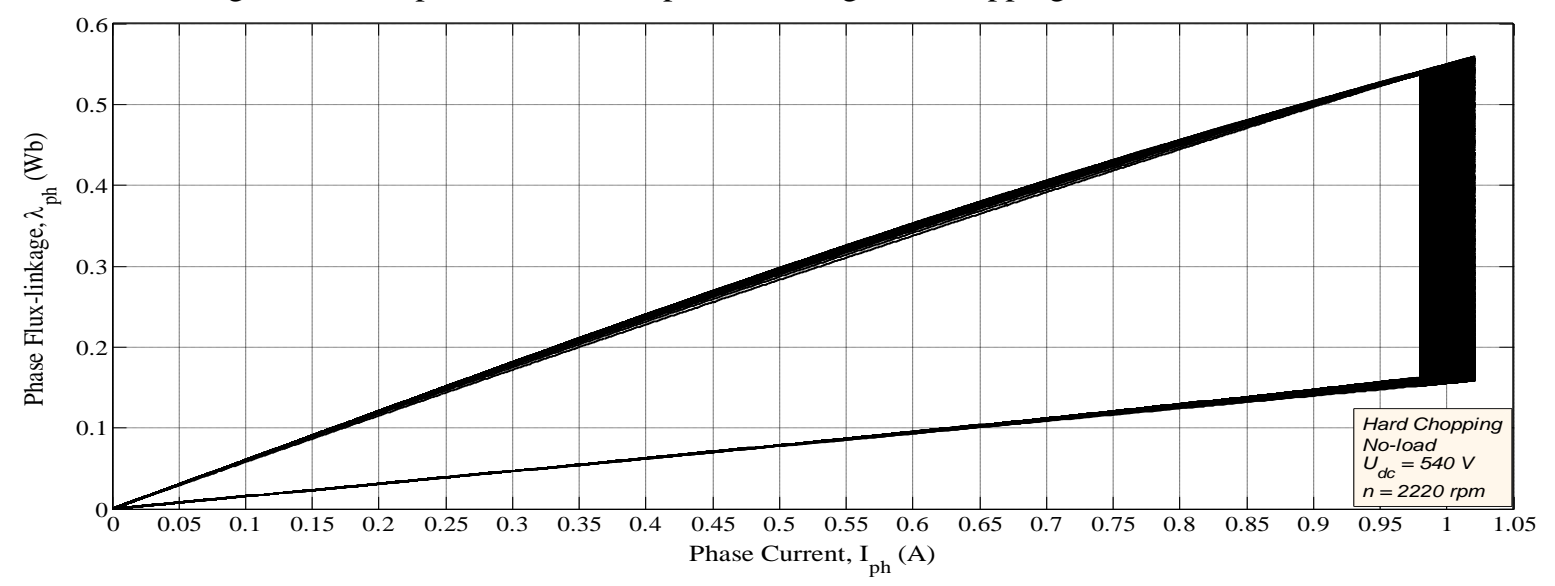

Fig. 15 Phase flux-linkage versus phase current using hard chopping control at $U_{\mathrm{dc}}=540 \mathrm{~V}$

\section{SOFT CHOPPING CONTROL OF CURRENT AT NO-LOAD}

The Simulink block control diagram when using hysteresis current control (soft chopping) for three phases 6/4 SRM at no load is shown in Fig. 16. The data required for this motor in the following block control diagram is obtained from Appendix (A). In soft chopping mode for asymmetric bridge, the lower switches are left on during phases conducting periods and the upper switches are chopped according to the pulsed signal in order to allows not only control of the current but also minimize the current ripples. Also, it produces less acoustic noise and less electromagnetic interference (EMI). The hysteresis band is desired to be as small as possible to reduce current ripples. Also, selecting the proper switching strategy, dwell angle, voltage source, and switching angles will improve the overall efficiency of the drive system. The switching angles are chosen such that the source current and total torque becomes has less ripple values. So, the switching used angle are turn-on angle, $\theta_{o n}=45^{\circ}$, and turn-off angle, $\theta_{\text {off }}=80^{\circ}$.

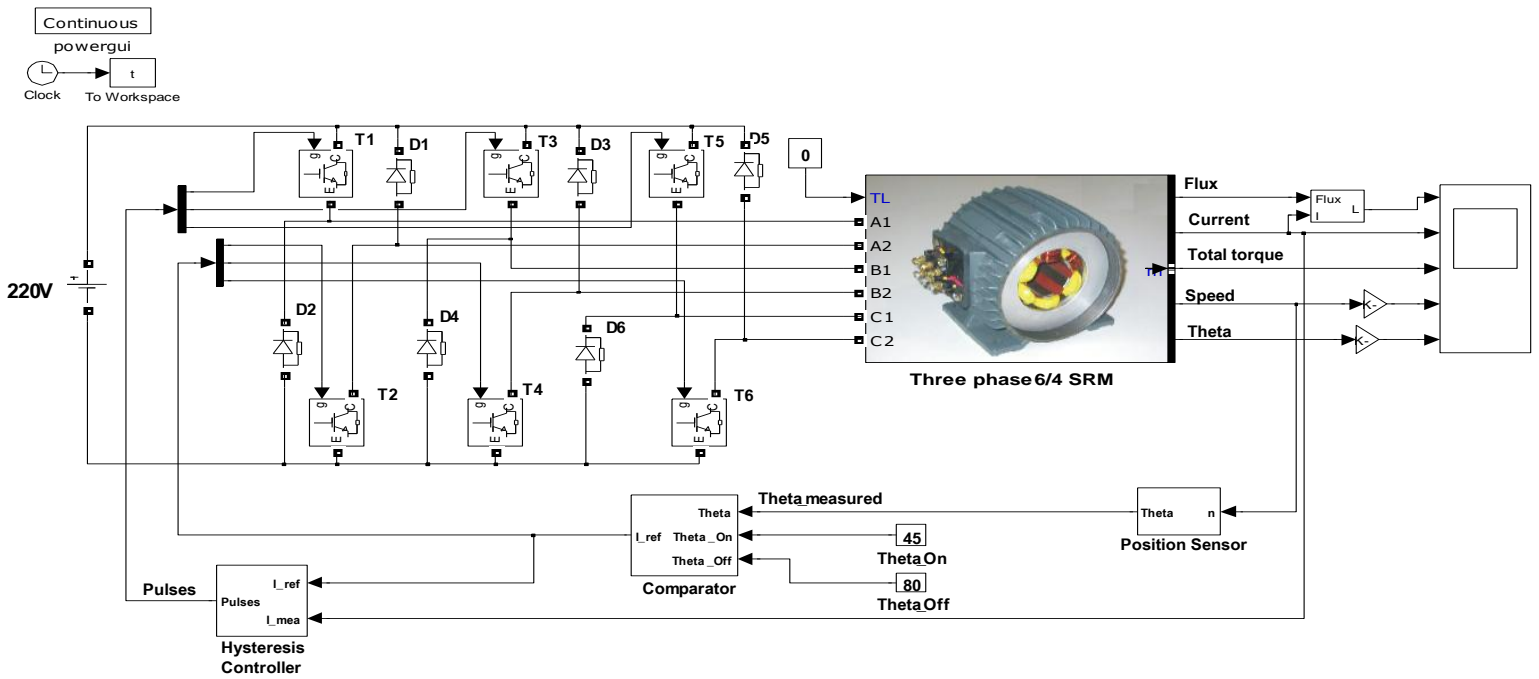

Fig. 16 Simulink model using soft chopping control for 3-ph 6/4 SRM at no-load 


\section{A. Soft chopping control with source voltage of $220 \mathrm{~V}$}

The machine characteristics; phases inductances, voltages and currents against rotor position using soft chopping control are shown in Fig. 17, where the rated converter voltage is $220 \mathrm{~V}$, but this voltage will be increased with loaded motor to increase the gradient of motor phases currents to produce flat-topped total current. The soft chopping mode is more suitable for motoring operation. The motor characteristics will be obtained at source voltage of 220,350 and $540 \mathrm{~V}$.
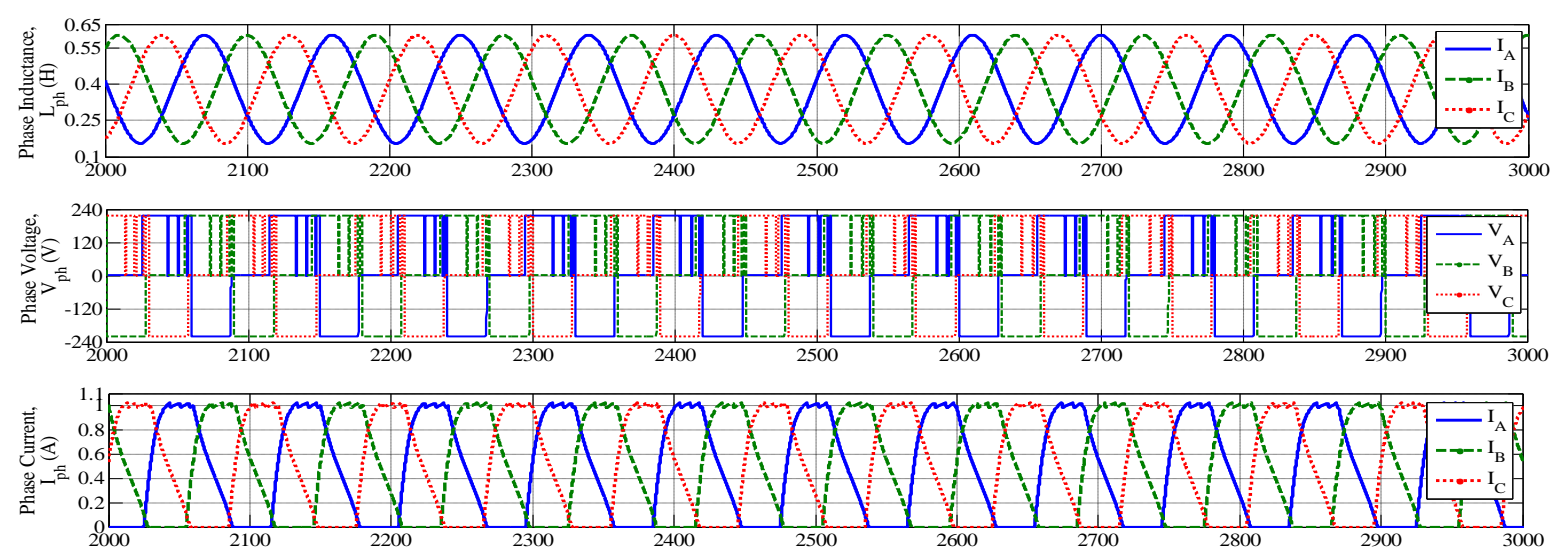

Rotor Position, $\theta$ (deg)

Fig. 17 Instantaneous phases inductances, voltages, and currents versus rotor position using soft chopping control at $\mathrm{U}_{\mathrm{dc}}=220 \mathrm{~V}$

The motor total torque versus rotor position using soft chopping at no-load with source voltage of $220 \mathrm{~V}$ is shown in Fig. 18. The torque ripple is smaller than that the case when hard chopping control is used at $220 \mathrm{~V}$. The motor speed reaches its steady state after about eight revolutions of the rotor as shown in Fig. 19. The phase flux-linkage versus phase current is shown in Fig. 20. The envelope area becomes larger than using hard chopping at $220 \mathrm{~V}$.

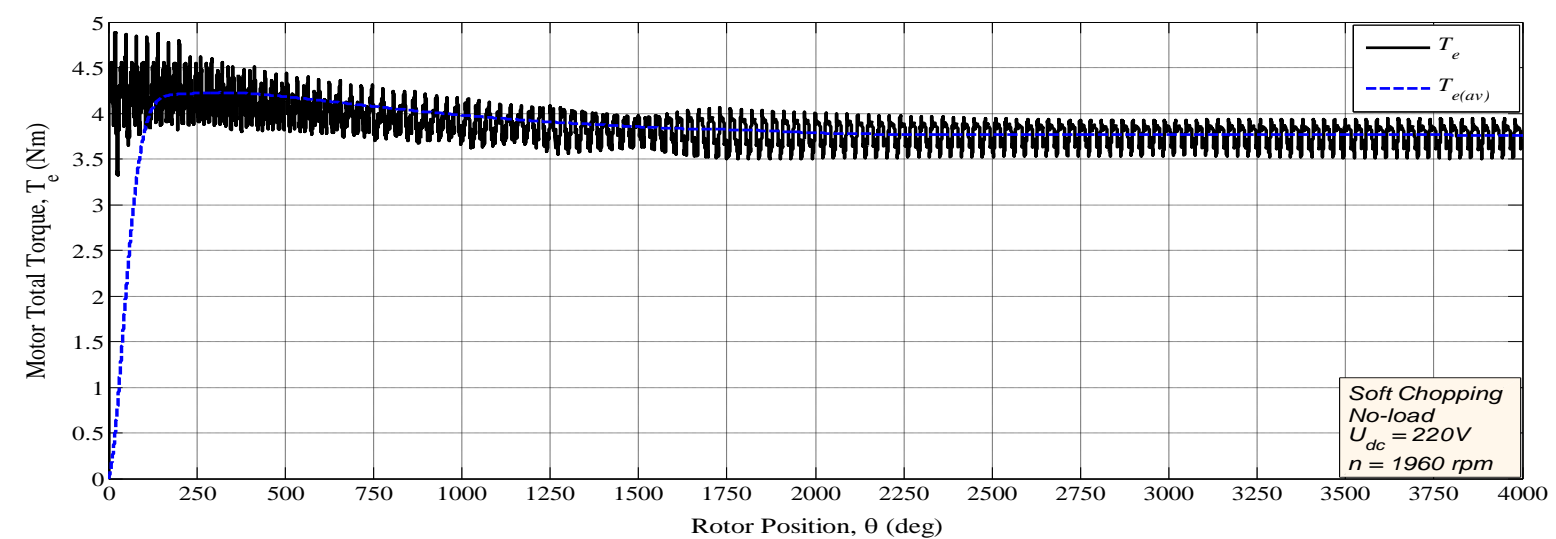

Fig. 18 Instantaneous total torque versus rotor position using soft chopping control at $U_{\mathrm{dc}}=220 \mathrm{~V}$

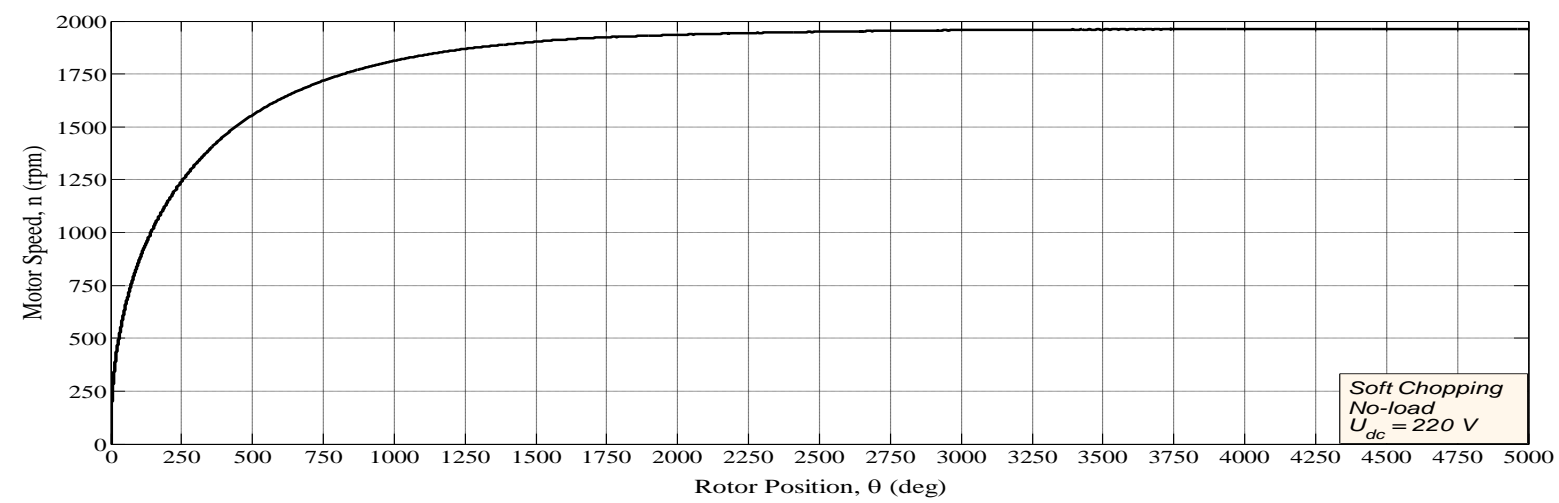

Fig. 19 Motor speed versus rotor position using soft chopping control at $U_{\mathrm{dc}}=220 \mathrm{~V}$ 


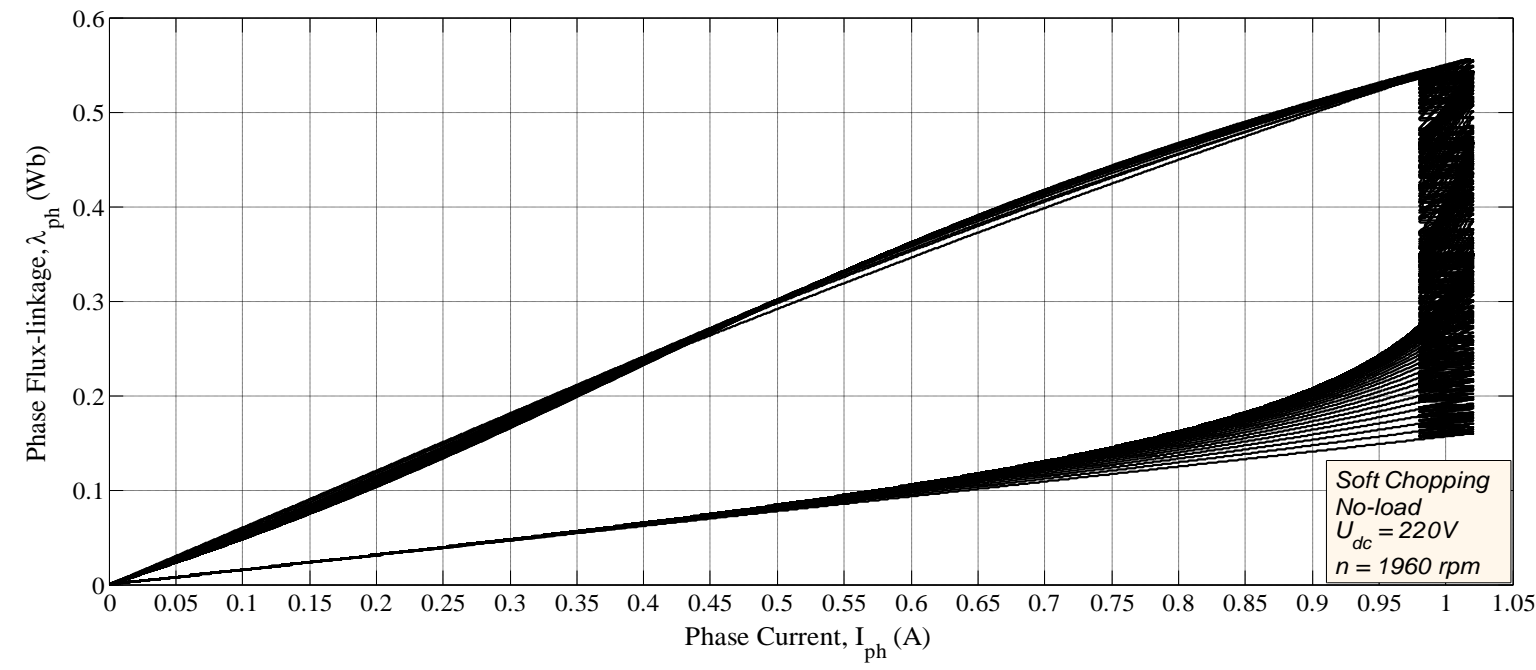

Fig. 20 Phase flux-linkage versus phase current using soft chopping control at $U_{\mathrm{dc}}=220 \mathrm{~V}$

\section{B. Soft chopping control with source voltage of $350 \mathrm{~V}$}

The simulation is repeated at applied source voltage $350 \mathrm{~V}$. Motor characteristics; phases inductances, phases voltages, and phases currents versus rotor position are shown in Fig. 21. By increasing the value of source voltage will results in increasing of the gradient of the phase current. The motor total torque versus rotor position is shown in Fig. 22, where the steady state of the total torque reaches faster than apply 220V, but it has larger ripple value.
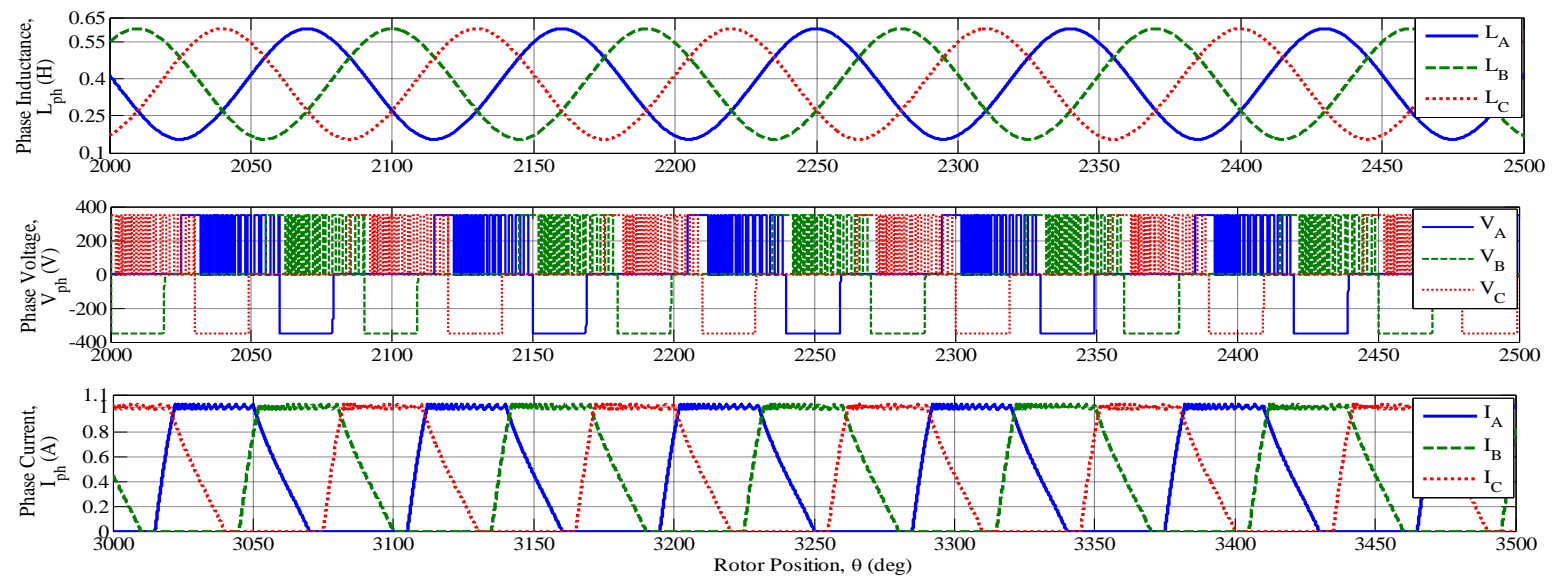

Fig. 21 Instantaneous phases inductances, voltages, and currents versus rotor position using soft chopping control at $\mathrm{U}_{\mathrm{dc}}=350 \mathrm{~V}$

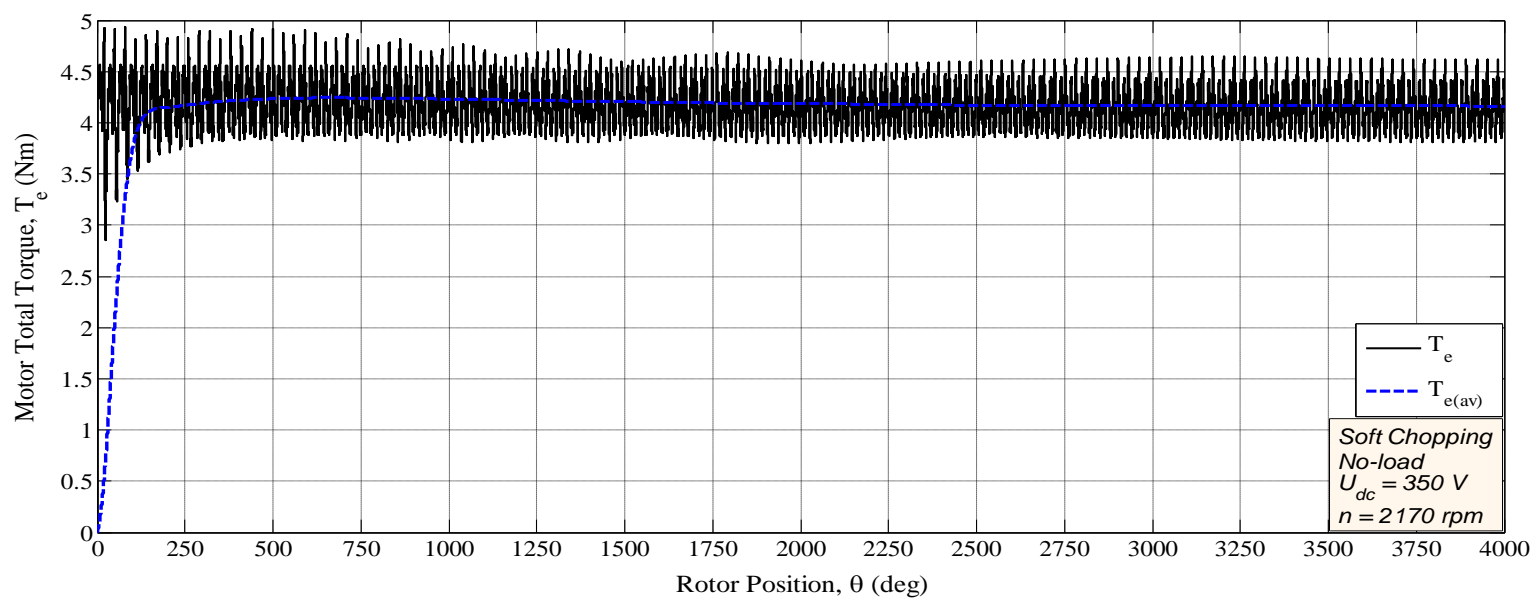

Fig. 22 Instantaneous total torque versus rotor position using soft chopping control at $U_{\mathrm{dc}}=350 \mathrm{~V}$ 


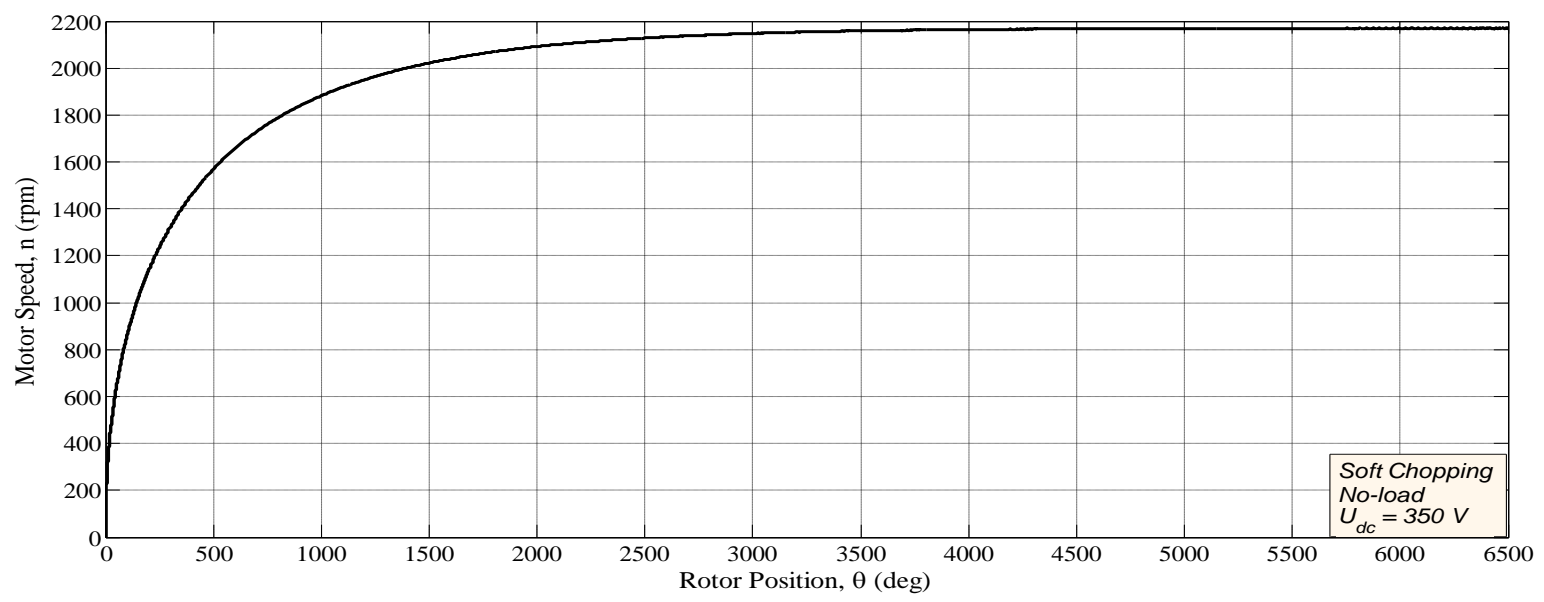

Fig. 23 Motor speed versus rotor position using soft chopping control at $U_{\mathrm{dc}}=350 \mathrm{~V}$

As shown in Fig. 23, the motor speed reaches its steady state after eleven revolutions. The steady state speed becomes $2170 \mathrm{rpm}$ that increases further with increasing supply voltage. The phase flux-linkage versus phase current is shown in Fig. 24.

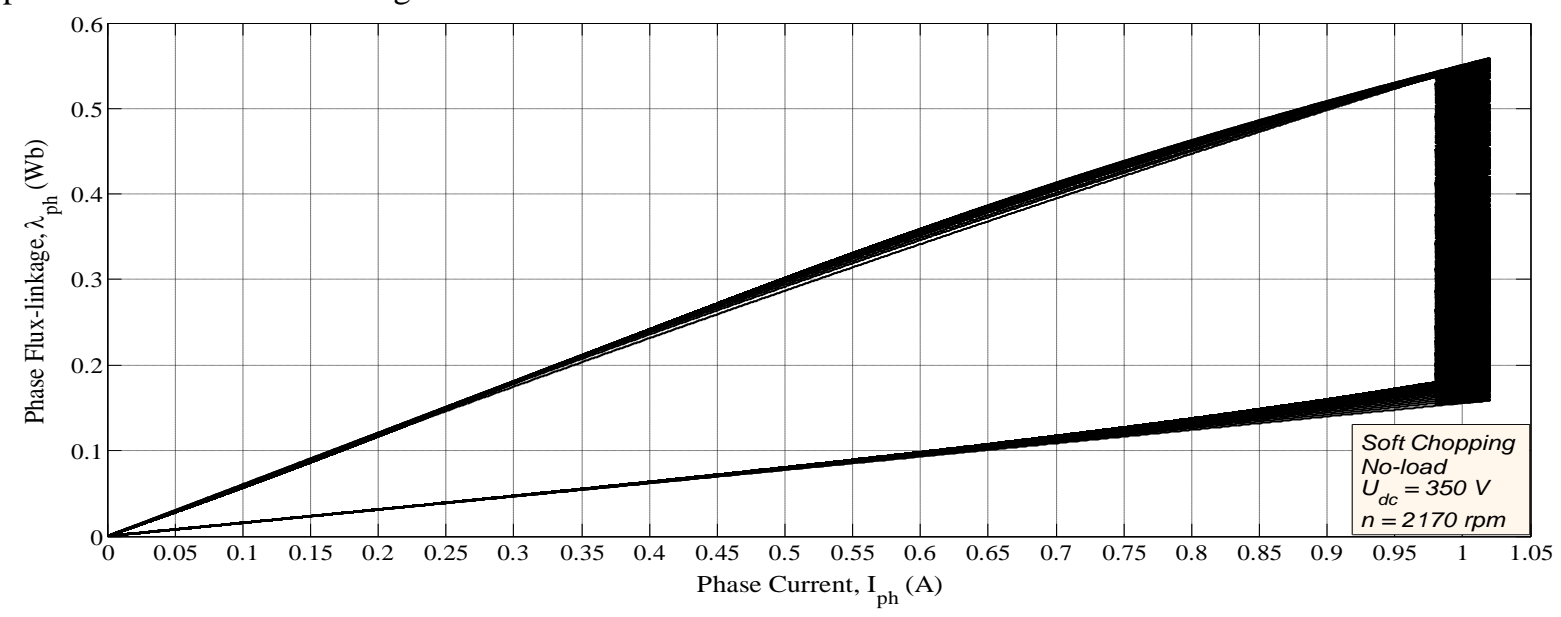

Fig. 24 Phase flux-linkage versus phase current using soft chopping control at $\mathrm{U}_{\mathrm{dc}}=350 \mathrm{~V}$

\section{Soft chopping control with source voltage of $540 \mathrm{~V}$}

The simulation is repeated at voltage $540 \mathrm{~V}$. Motor characteristics; phase inductance, phase voltage, and phase current versus rotor position are shown in Fig. 25 producing further increase in the gradient of the current.
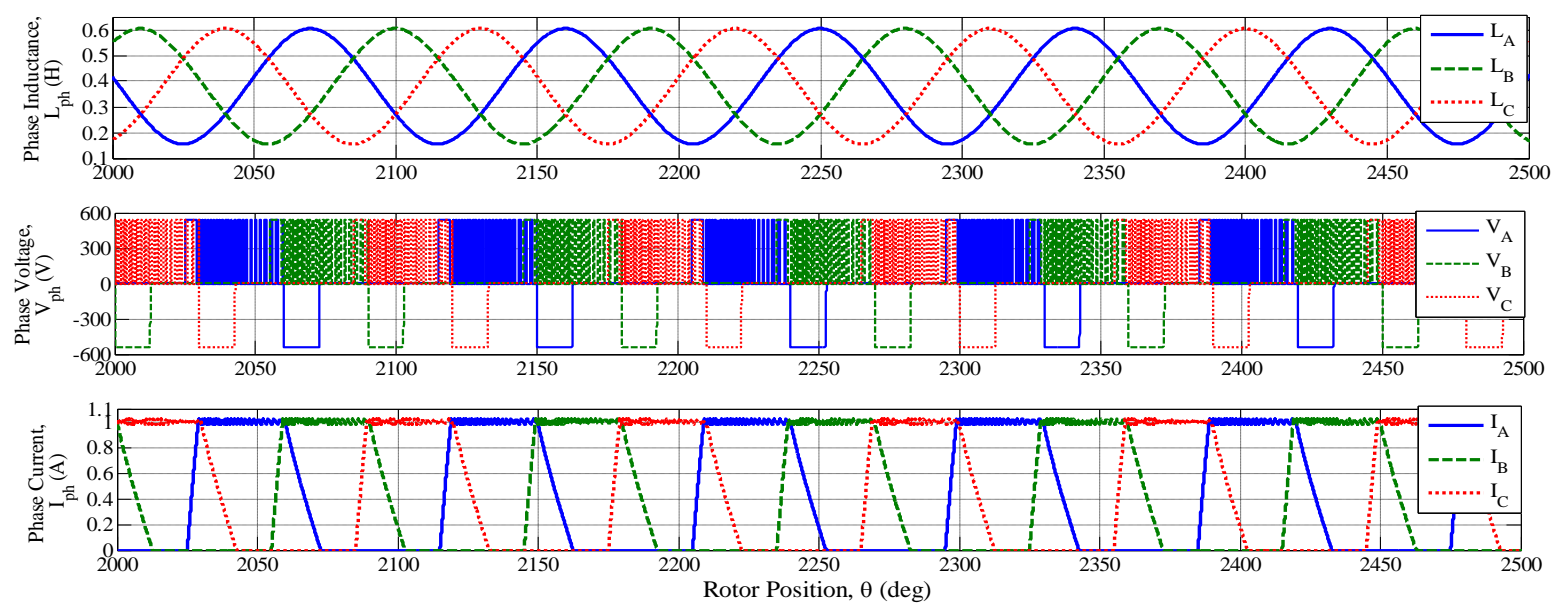

Fig. 25 Instantaneous phases inductances, voltages, and currents versus rotor position using soft chopping control at $\mathrm{U}_{\mathrm{dc}}=540 \mathrm{~V}$ 


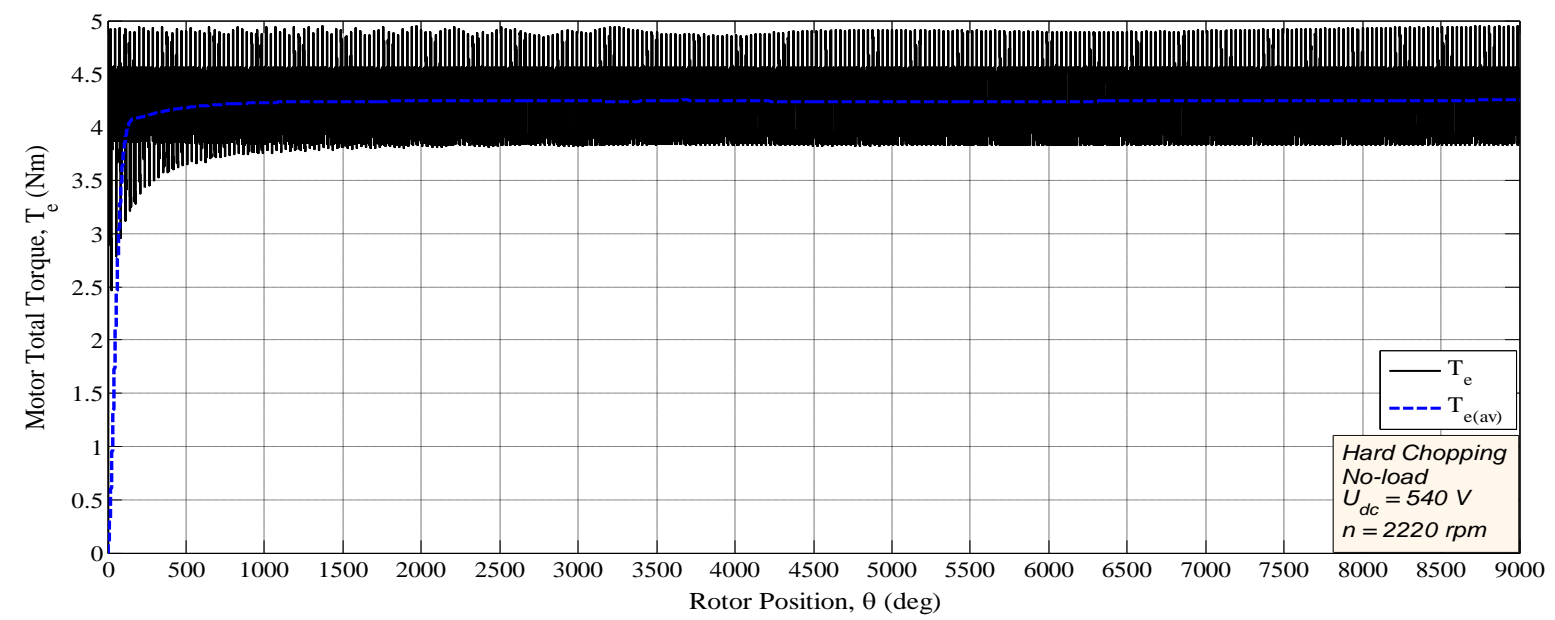

Fig. 26 Instantaneous total torque versus rotor position using soft chopping control at $\mathrm{U}_{\mathrm{dc}}=540 \mathrm{~V}$

The motor total torque versus rotor position is shown in Fig. 26, where the total torque reaches to steady state faster than apply: $220 \mathrm{~V}$ or $350 \mathrm{~V}$, but it has larger ripple value. From Fig. 27 , the motor speed reaches its steady state after fourteen revolutions. The steady state speed becomes $2220 \mathrm{rpm}$ that increases further with increasing supply voltage. The phase flux-linkage versus phase current with source voltage $540 \mathrm{~V}$ is shown in Fig. 28.

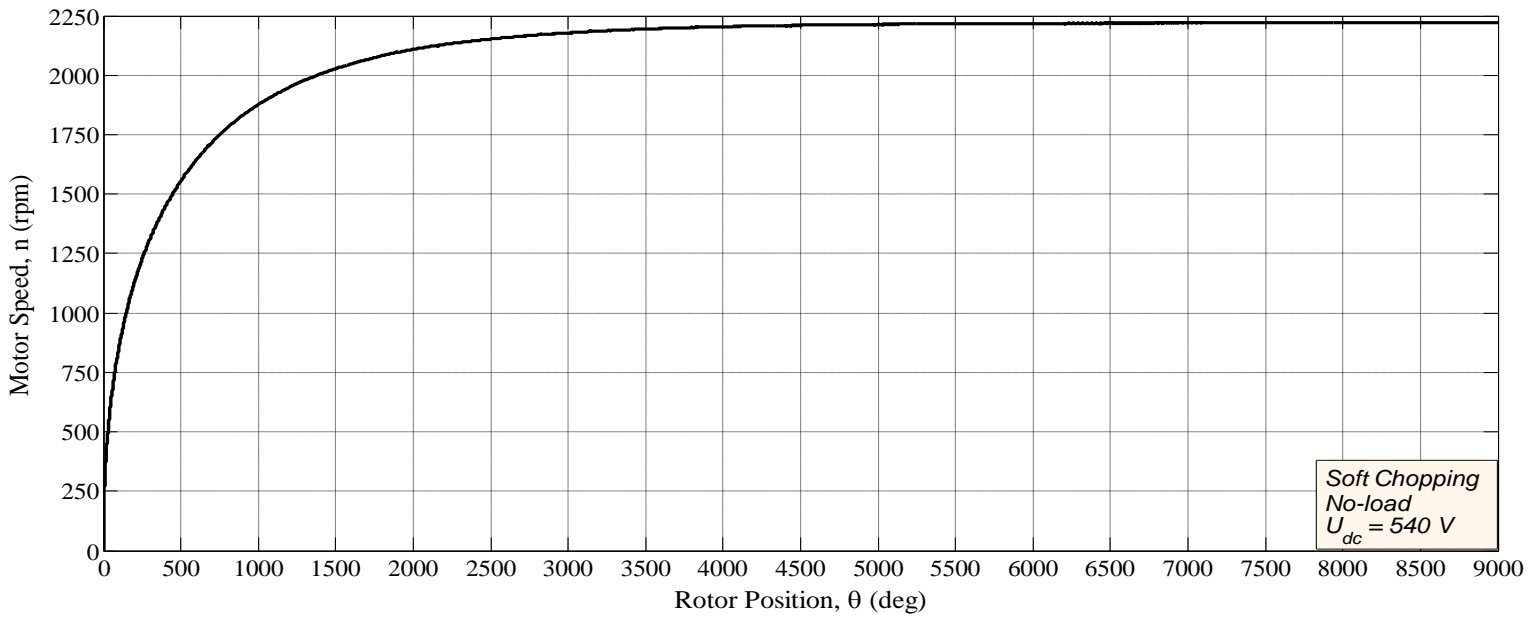

Fig. 27 Motor speed versus rotor position using soft chopping control at $U_{\mathrm{dc}}=540 \mathrm{~V}$

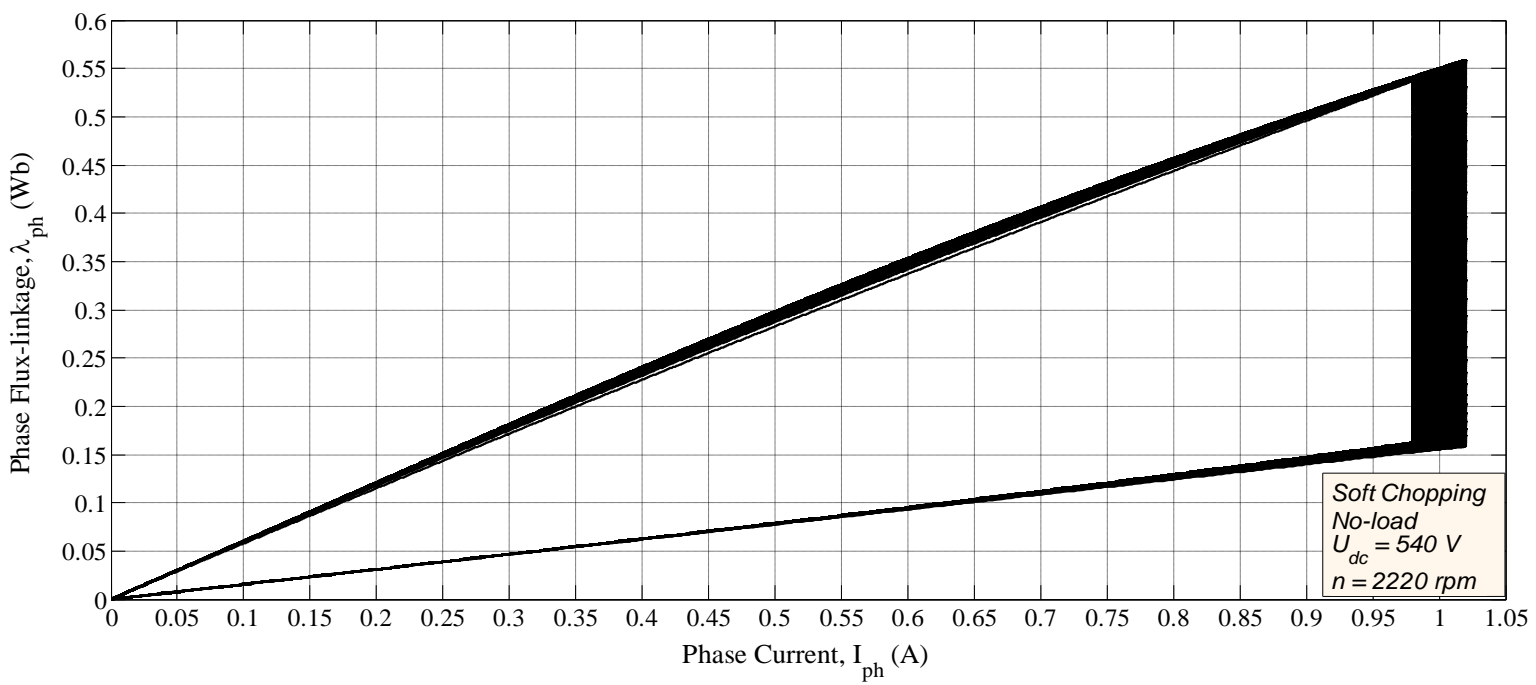

Fig. 28 Phase flux-linkage versus phase current using soft chopping control at $\mathrm{U}_{\mathrm{dc}}=540 \mathrm{~V}$ 


\section{AVERAGE MOTOR CHARACTERISTICS AT NO-LOAD}

To compare the operations of asymmetric bridge converter at using hard or soft chopping, the average characteristics is presented. In this section; average source current, average total torque, average total torque per ampere, and motor speed versus rotor position is introduced with different source voltage by using turn-on switching angle equals $45^{\circ}$ and turn-off switching angle equals $80^{\circ}$. The main idea for using these switching angles are that to produce average characteristics with less ripples for producing more precise operation of less acoustic noise.

We must note that the different values of used voltages in comparison are the voltages that can be used in aircraft applications with SRM converter.

\section{A. Average characteristics with hard chopping}

Hard chopping control with $\theta_{o n}=45^{\circ}$ and $\theta_{o f f}=80^{\circ}$ by applying different source voltages $220,350,540 \mathrm{~V}$ is used in this section to obtain average characteristics of SRM as function of rotor position. The average source current versus rotor position is shown in Fig. 29, the average source current is decreased due to the increasing of switching frequency with increasing the source voltage.

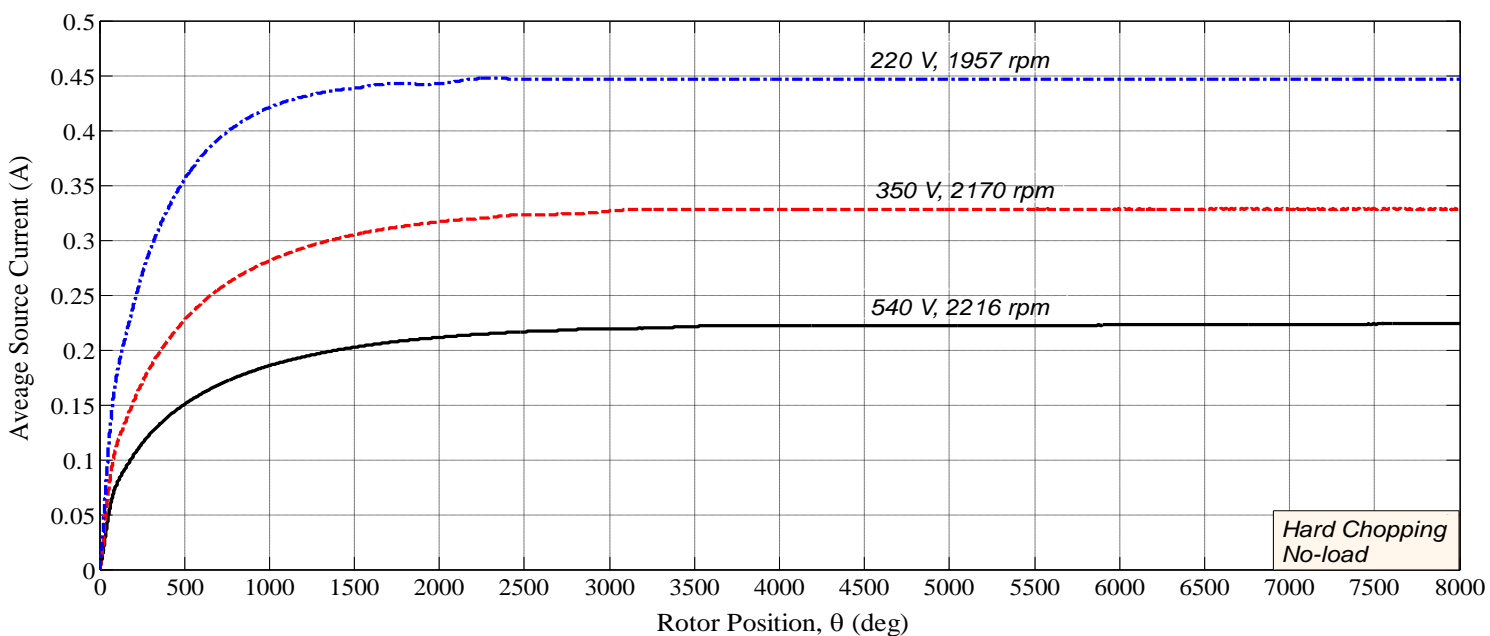

Fig. 29 Average source current versus rotor position for hard chopping at no-load for different source voltage

The average total torque versus rotor position with different source voltage that used in aircraft applications is shown in Fig. 30. The average total torque decreases with decreasing the source voltage. With low voltage, the total torque reaches steady state faster. But, for most precise operation of SRM, the average total torque per ampere is the most powerful characteristic than the average total torque. The average total torque per ampere versus rotor position is presented in Fig. 31. The torque per ampere increases as the voltage source increases. As shown in Fig. 32, the motor speed increases as the voltage source increases.

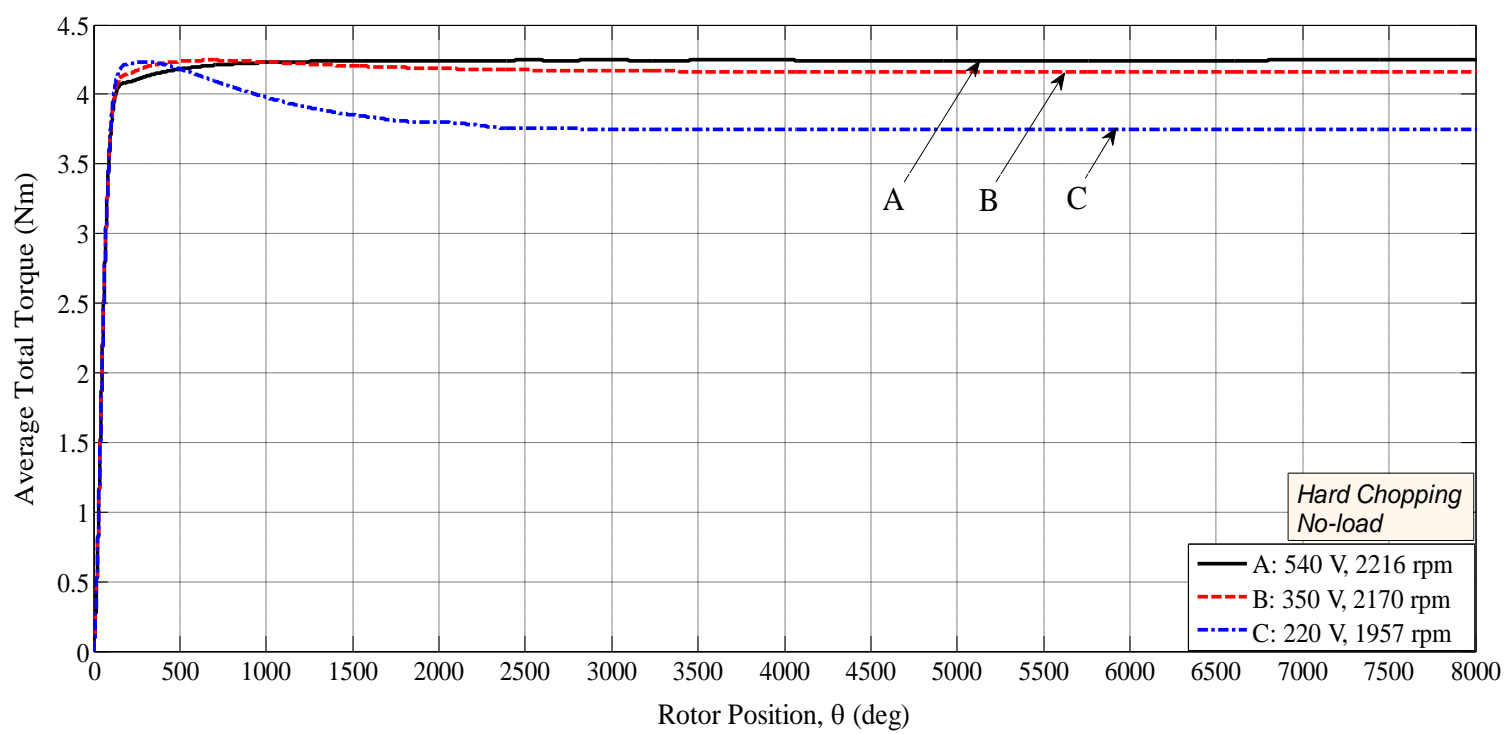

Fig. 30 Average total torque versus rotor position for hard chopping at no-load for different source voltage 


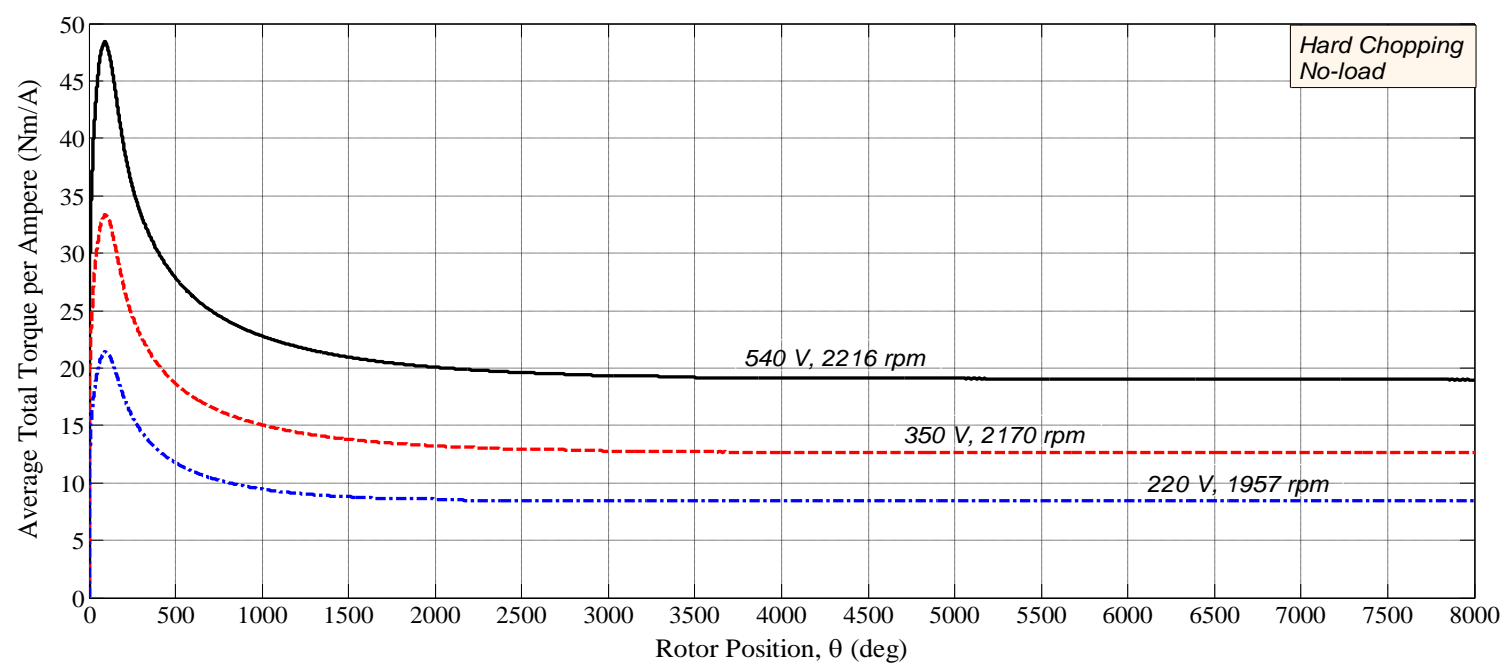

Fig. 31 Average total torque per ampere versus rotor position for hard chopping at no-load for different source voltage

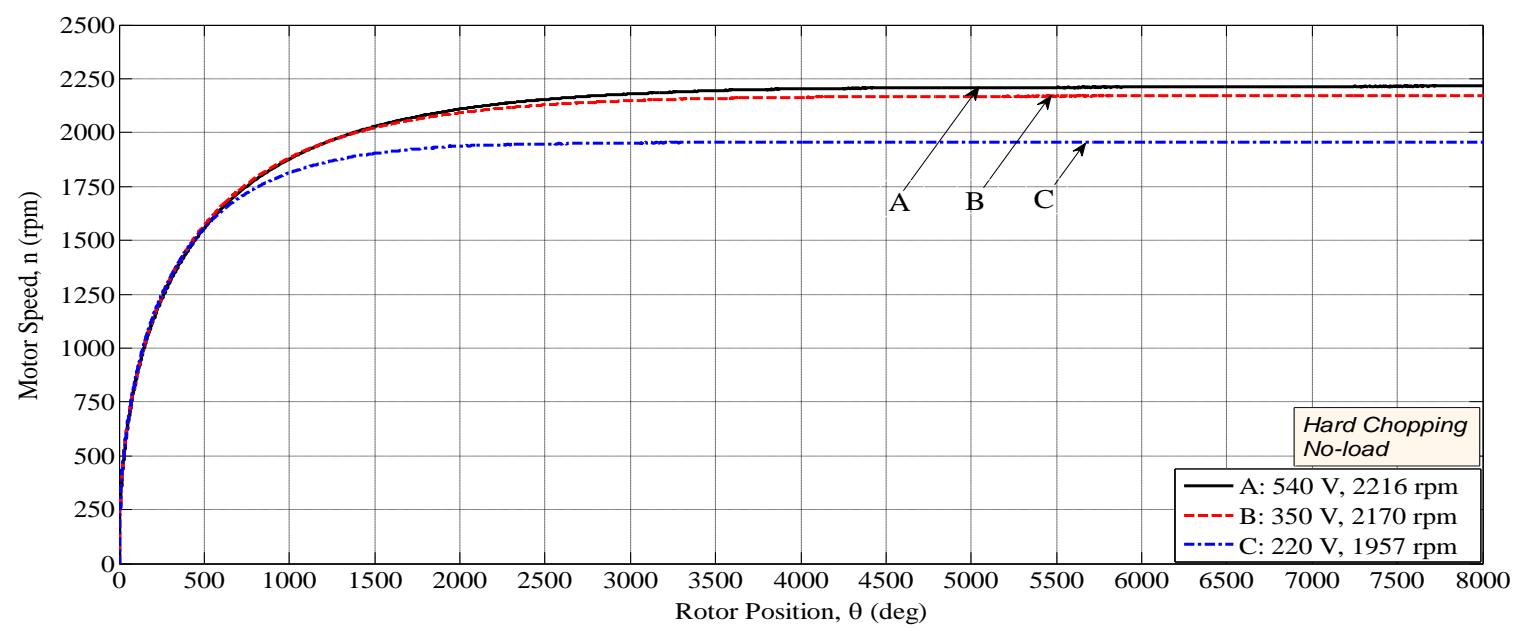

Fig. 32 Motor speed versus rotor position for hard chopping at no-load for different source voltage

\section{B. Average characteristics with soft chopping}

The average source current versus rotor position at using soft chopping with different applied source voltage is shown in Fig. 33. The current is decreased with increasing the source voltage depending on the switching frequency that increases with increasing the source voltage. The average total torque versus rotor position when the soft chopping is used with different source voltage is shown in Fig. 34. As the voltage source increases, the total torque increases. Also, the average total torque per ampere and motor speed increase versus rotor position increases with increasing the source voltage as shown in Fig. 35 and Fig. 36 respectively.

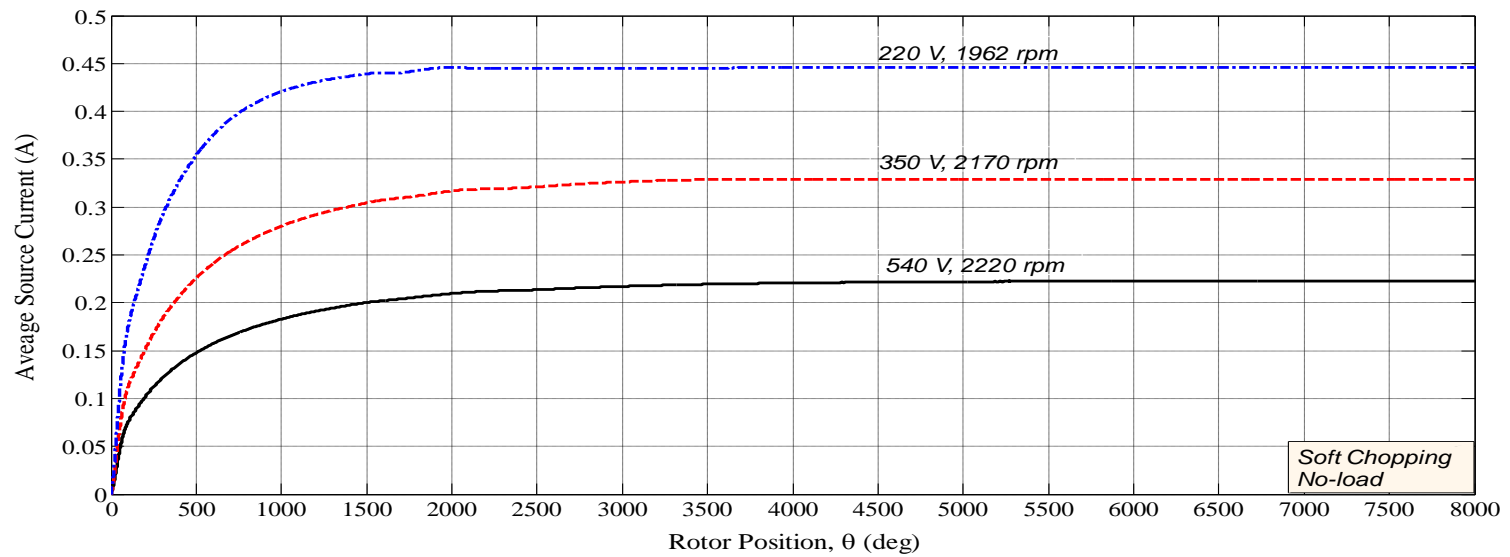

Fig. 33 Average source current versus rotor position for soft chopping at no-load for different source voltage 


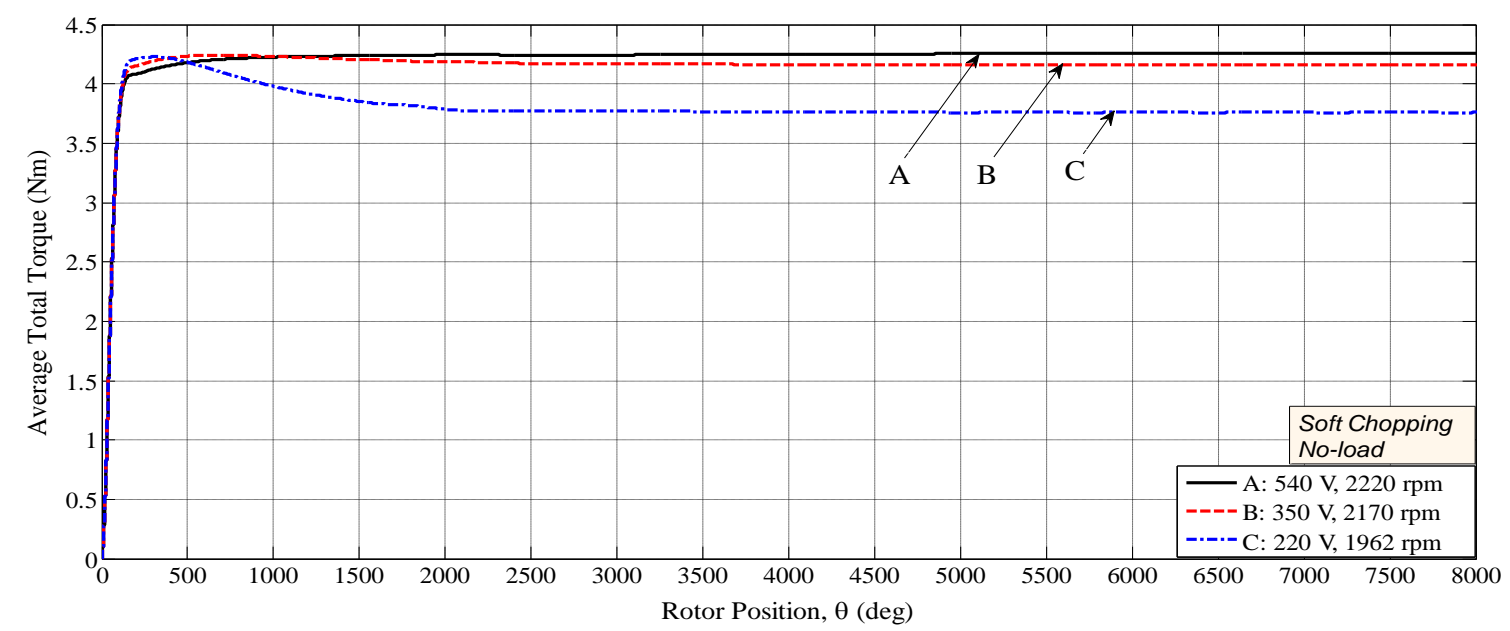

Fig. 34 Average total torque versus rotor position for soft chopping at no-load for different source voltage

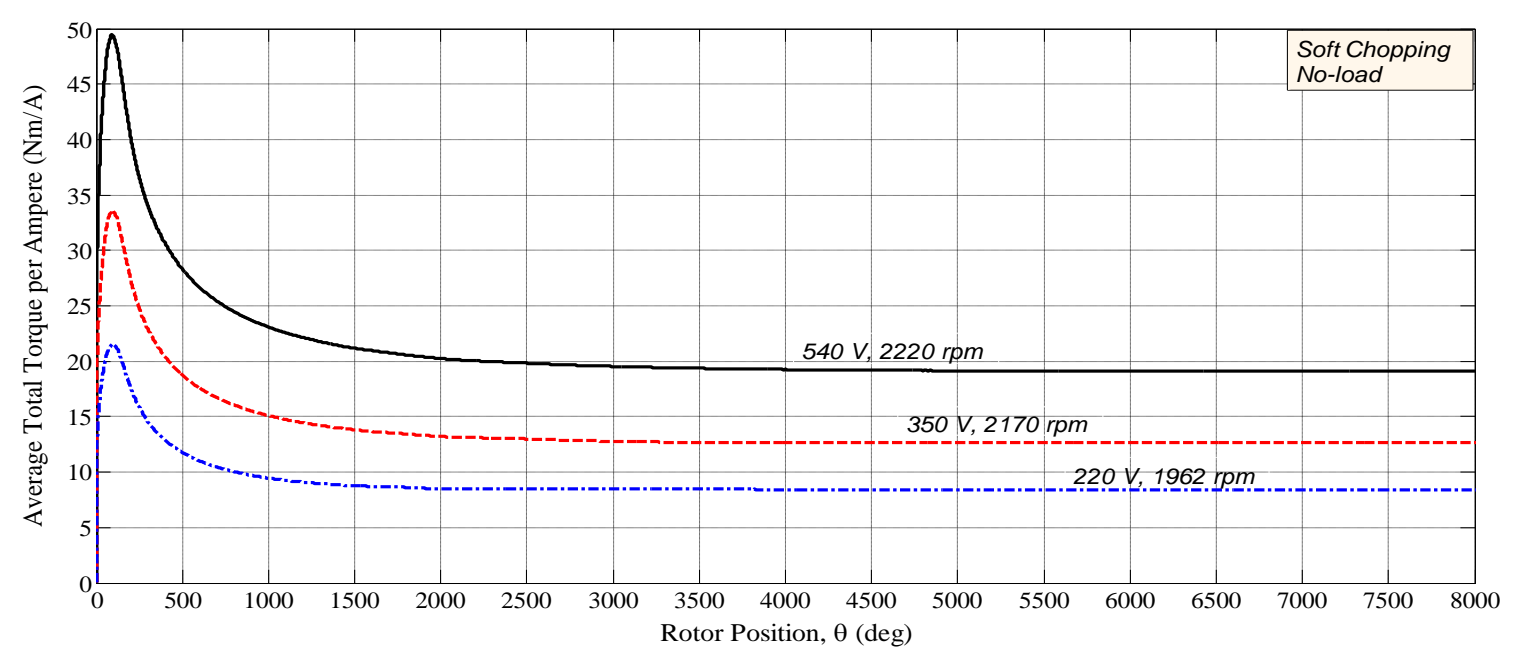

Fig. 35 Average total torque per ampere versus rotor position for soft chopping at no-load for different source voltage

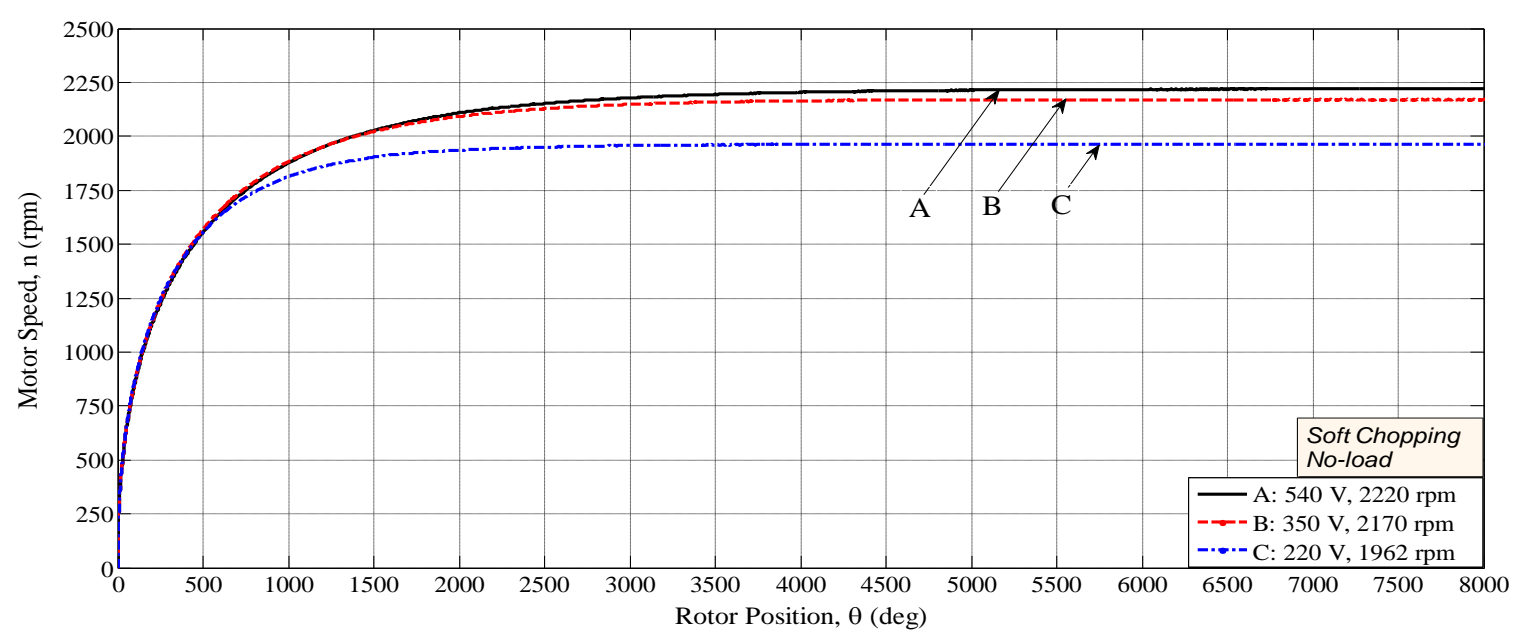

Fig. 36 Motor speed versus rotor position for soft chopping at no-load for different source voltage

\section{Comparison between average characteristics for soft and hard chopping}

Table I shows the comparison between motor characteristics at different source voltage; where, $U_{d c}, I_{s}$, $T_{e}, T_{e} / I_{s}$ and $n$ are the DC source voltage, average source current, average total torque, average total torque per ampere, and motor speed respectively. 
TABLE I

STEADY STATE VALUES OF MOTOR CHARACTERISTICS AT DIFFERENT SOURCE VOLTAGES

\begin{tabular}{|c|c|c|c|c|c|c|c|c|}
\hline \multirow{2}{*}{$C h / s$} & \multicolumn{4}{|c|}{ Soft Chopping } & \multicolumn{4}{c|}{ Hard Chopping } \\
\cline { 2 - 9 }$U_{d c}(V)$ & $\begin{array}{c}I_{s} \\
(A)\end{array}$ & $\begin{array}{c}T_{e} \\
(\mathrm{Nm})\end{array}$ & $\begin{array}{c}T_{e} / I_{s} \\
(\mathrm{Nm} / \mathrm{A})\end{array}$ & $\begin{array}{c}n \\
(\mathrm{rpm})\end{array}$ & $\begin{array}{c}I_{s} \\
(A)\end{array}$ & $T_{e}(\mathrm{Nm})$ & $\begin{array}{c}T_{e} / I_{s} \\
(\mathrm{Nm} / A)\end{array}$ & $n(\mathrm{rpm})$ \\
\hline 540 & 0.2229 & 4.255 & 19.09 & 2220 & 0.2239 & 4.25 & 18.98 & 2216 \\
\hline 350 & 0.3294 & 4.16 & 12.629 & 2170 & 0.3284 & 4.159 & 12.66 & 2170 \\
\hline 220 & 0.4457 & 3.759 & 8.434 & 1962 & 0.4463 & 3.75 & 8.4 & 1957 \\
\hline
\end{tabular}

\section{CONCLUSIONS}

The investigation in this paper indicates that the control parameters and outputs under the current hysteresis chopping control can affect in SRM drives. The current hysteresis chopping control is one of the important control methods for SRM drives. It is often used during speed operation of SRM drives. At steady state operation, for motor parameters comparison at different source voltage with constant switching angles; then:

The average source current is inversely proportional to increase of source voltage.

- The average total torque is directly proportional to increase of source voltage.

The average total torque per ampere is directly proportional to increase of source voltage.

The motor speed is directly proportional to increase of source voltage.

The hysteresis control cannot be implemented without closed loop control. There is no limitation of high switching frequency without using additional circuitry to the drive system, but if faster switching devices are used to limit the high switching losses and noise, the cost of the control system will be much increased. Also, the chopping strategy allows a very precise current control because the hysteresis band is a design parameter, but acoustic and electromagnetic noise is difficult to be filtered because the high switching frequency of converter switches.

\section{APPENDIX A: MOTOR PARAMETERS}

The parameters of the three phase 6/4 poles SRM are:

Number of motor phases $\quad: K=3$

Number of stator poles $\quad: N_{S}=6$

Number of rotor poles $\quad: N_{R}=4$

Stator pole arc (mech. deg.) $: \beta_{S}=40^{\circ}$

Rotor pole arc (mech. deg.) $: \beta_{R}=45^{\circ}$

DC voltage rating $\quad: U_{d c}=220 \mathrm{~V}$

Stator phase resistance $\quad: R=17 \Omega$

Aligned inductance $\quad: L_{a l}=0.605 \mathrm{H}$

Unaligned inductance

$\begin{array}{ll}\text { Viscous friction coefficient } & : B=0.0183 \mathrm{~N} \cdot \mathrm{m} \cdot \mathrm{Sec}^{2} \\ \text { Rated speed } & : n_{r}=1000 \mathrm{rpm} \\ \text { Rated phase current } & : I_{r}=3 \mathrm{~A} \\ \text { Rated torque } & : T_{e}=1 \mathrm{Nm} \\ \text { Number of turns per phase } & : N_{p h}=600 \\ \text { Winding wire diameter } & : d=0.5 \mathrm{~mm} \\ \text { Rotor pole arc (mech. deg.) } & : \theta_{r}=30^{\circ} \\ \text { Inertia constant } & : J=0.0013 \mathrm{Kg} \cdot \mathrm{m}^{2}\end{array}$

\section{ACKNOWLEDGEMENTS}

Many thanks to the professors and colleagues in Electrical Engineering Department, Benha University and the team of Electronics Research Institute for helpful and encouragement.

\section{REFERENCES}

[1] Samia M. Mahmoud, Mohsen Z. El-Sherif, Emad S. Abdel-Aliem, and Maged N. F. Nashed, Studying Different Types of Power Converters Fed Switched Reluctance Motor, International Journal of Electronics and Electrical Engineering Vol. 1, No. 4, Dec. 2013, 281-290.

[2] Ahmed Abdel-Hafez, Power Generation and Distribution System for a More Electric Aircraft - A Review, in Dr. Ramesh K. Agarwal (Ed.), Recent Advances in Aircraft Technology, 2012 (InTech Publisher), 289-308.

[3] Hamid Ehsan Akhter et al., Determination of optimum switching angles for speed control of switched reluctance motor drive system, Indian Journal of Engineering and Materials Sciences, Vol. 11, June 2004, 151-168.

[4] R. Krishnan, Switched Reluctance Motor Drives: Modeling, Simulation, Analysis, Design, and Applications (CRC Press 2001).

[5] Praveen Vijayraghavan, Design of Switched Reluctance Motors and Development of a Universal Controller for Switched Reluctance and Permanent Magnet Brushless DC Motor Drives, doctoral diss., Faculty of the Virginia Polytechnic Institute and State University, Blacksburg, Virginia, November 2001. 
[6] Dong-Hee Lee, So-Yeon Ahn and Jin-Woo Ahn, Advanced Torque Control Scheme for the High Speed Switched Reluctance Motor, in Mukhtar Ahmad (Ed.), Advances in Motor Torque Control, 2011 (InTech Publisher), 87-114.

[7] K.C. Agrawal, Industrial Power Engineering and Applications Handbook (Newnes Power Engineering Series 2001).

[8] E. S. Elwakil and M. K. Darwish, Critical Review of Converter Topologies For Switched Reluctance Motor Drives, IREE International Review of Electrical Engineering, Vol. 2, No. 1, January-February 2007. 50-58.

[9] Kiran Srivastava et al., Simulation and Modeling of $8 / 6$ Switched Reluctance Motor Using Digital Controller, International Journal of Electronics Engineering, Vol. 3, No. 2, 2011, 241-246.

[10] Yilmaz Sozer et al., Automatic control of excitation parameters for switched-reluctance motor drives, IEEE Trans., Vol. 18, Issue: 2, March 2003. 594-603.

[11] Jin-Woo Ahn, Switched Reluctance Motor, in Moulay Tahar Lamchich (Ed.), Torque Control, 2011 (InTech Publisher), 201-252.

[12] Catalin S. Dragu and Ronnie Belmans, Optimal Firing Angles Control For Four-Quadrant Operation of an 8/6 SRM, Proc. 10th EPE Conf. on Power Electronics and Applications, France, Toulouse, 2003, 110.

[13] C. Mademlis and I. Kioskeridis, Performance Optimization in Switched Reluctance Motor Drives with Online Commutation Angle Control, IEEE Trans. Energy Conversion, Vol. 18, Sept. 2003, 448-457.

[14] Radim Visinka, 3-Phase Switched Reluctance (SR) Sensorless Motor Control Using a 56F80x, 56F8100 or 56F8300 Device, Freescale Semiconductor, Application Note, AN1932, Rev. 2, February 2005.

\section{BIOGRAPHY}

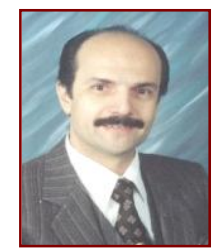

Mohsen Z. El-Sherif received his B.S. degree in 1970 from Electrical Engineering from El-Mansoura University, Egypt. In 1975, he worked as an engineer in Higher-Technical Institute at Shoubra, Egypt. In 1982, he received his M.S. degree from Cairo University, Egypt. From November 1985 untill May 1987, he worked as a guest researcher at Kyushu Institute of Technology, Japan. In December 1987 he received Ph.D. degree in Electrical drives from Cairo University, Egypt. In 1987-1993, he worked as a Lecturer of Electrical Engineering and Electrical Machines at Zagazig University, Egypt. In 1993, he worked as Associate Professor at Shoubra Faculty of Engineering, Zagazig University. In December 1999 he was promoted to Professor's degree in the same Faculty of Engineering. In 2000 - up till now, he works as a Professor of Electrical Machines at Shoubra Faculty of Engineering, Benha University, Cairo, Egypt. His current research interests include electrical engineering, power electronics, electrical machines and drives.

For contact; e-mail address: m.elsherif@feng.bu.edu.eg

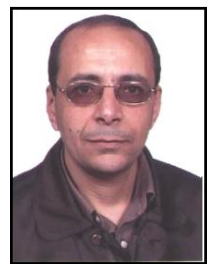

Maged N. F. Nashed received his B.S. degree in Electrical Engineering, from Menoufia University, Egypt, in May 1983, his Diploma of Higher Studies from Cairo University, May 1990, his M.SC. degree in Electrical Engineering, from Ain Shams University, Cairo, Egypt, in April 1995 and his Ph.D. in Electrical Engineering, from Ain Shams University, Cairo, Egypt, in January 2001. He was a researcher for Fukuoka Institute of Technology, Japan, 2005. Since 1989, he has been a researcher with the Department of Power Electronic and Energy Conversion, Electronic Research Institute. From 2008 works as associate professor of power electronics in the same Institute. He is engaged in research on power electronics; drive circuit, control of drives and renewable energy.

For contact; e-mail address: maged@eri.sci.eg

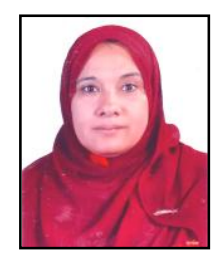

Samia M. Mahmoud received her B.S. degree in 1984 from faculty of Electrical Engineering, Benha University, Egypt. In November 11, 1999, she received her M.S. from Electrical Engineering and Electrical Machines at Zagazig University, Egypt. In October, 2004, she received Ph.D. degree in Electrical Engineering from Benha University, Egypt. In 2005- till now, she works as a lecturer of Electrical Engineering at Shoubra Faculty of Engineering, Benha University, Cairo, Egypt. Her current research interests include wind turbine energy, electrical machines and drives.

For contact; e-mail address: samia.ibrahim@feng.bu.edu.eg

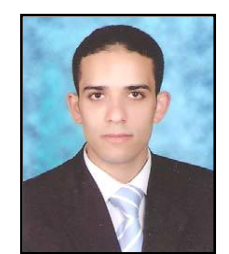

Emad S. Abdel-Aliem received his B.S. \& M.Sc. degree from Electrical Engineering, Shoubra Faculty of Engineering, Benha University, Cairo, Egypt, in May 2006 and December 2011 respectively. He works now on Ph.D. degree in this College. In 2006-2012 \& 2012 up till now, he works as a demonstrator and an Assistant Lecturer at Shoubra Faculty of Engineering, Benha University, Cairo, Egypt respectively. He has worked extensively in studying stepping motor and switched reluctance motor drives.

For contact; e-mail address: emad.sami@feng.bu.edu.eg 